Illinois State University

ISU ReD: Research and eData

Theses and Dissertations

$4-11-2014$

\title{
Crime And Poverty In Detroit: A Cross-Referential Critical Analysis Of Ideographs And Framing
}

Jacob Jerome Nickell

Illinois State University, jjnicke@ilstu.edu

Follow this and additional works at: https://ir.library.illinoisstate.edu/etd

Part of the Mass Communication Commons, and the Rhetoric Commons

\section{Recommended Citation}

Nickell, Jacob Jerome, "Crime And Poverty In Detroit: A Cross-Referential Critical Analysis Of Ideographs And Framing" (2014). Theses and Dissertations. 167.

https://ir.library.illinoisstate.edu/etd/167

This Thesis is brought to you for free and open access by ISU ReD: Research and eData. It has been accepted for inclusion in Theses and Dissertations by an authorized administrator of ISU ReD: Research and eData. For more information, please contact ISUReD@ilstu.edu. 


\title{
CRIME AND POVERTY IN DETROIT: A CROSS-REFERENTIAL CRITICAL ANALYSIS OF IDEOGRAPHS AND FRAMING
}

\author{
Jacob J. Nickell
}

135 Pages

May 2014

This thesis examines how the relationship between crime and poverty is rhetorically constructed within the news media. To this end, I investigate the content of twelve news articles, published online, that offered coverage of crime in the city of Detroit, Michigan. I employ three methods in my criticism of these texts: ideographic analysis, critical framing analysis, and an approach that considers ideographs and framing elements to be rhetorical constructions that function together. In each phase of my analysis, I developed ideological themes from concepts emerging from the texts. I then approached my discussion of these findings from a perspective of Neo-Marxism, primarily using Gramsci's (1971) critique of cultural hegemony to inform my conclusions. I ultimately argue that, through their dissemination of these representations, the news media function as a mechanism to perpetuate an ideology of classism. 
CRIME AND POVERTY IN DETROIT: A CROSS-REFERENTIAL CRITICAL ANALYSIS OF IDEOGRAPHS AND FRAMING

\section{JACOB J. NICKELL}

A Thesis Submitted in Partial Fulfillment of the Requirements for the Degree of

MASTER OF SCIENCE

School of Communication

\section{ILLINOIS STATE UNIVERSITY}


CRIME AND POVERTY IN DETROIT: A CROSS-REFERENTIAL CRITICAL ANALYSIS OF IDEOGRAPHS AND FRAMING

JACOB J. NICKELL

COMMITTEE MEMBERS:

Joseph P. Zompetti, Chair

John R. Baldwin

K. Megan Hopper 


\section{ACKNOWLEDGEMENTS}

I owe the utmost gratitude to Dr. Joseph Zompetti. Z, you always know when to praise me and when to "light a fire" to ensure that I am focusing on my work. Your encouragement, advice, and incredible ability to read vast amounts of text in short periods of time were all invaluable, and you have helped me improve as a student and scholar. I also would like to thank the rest of my committee, Dr. John Baldwin and Dr. Megan Hopper, whose insightful contributions helped me refine and extend this project.

There are a number of other people who have offered me support throughout this experience: Chris, “my same," as well as my indefatigable source of rational perspective; Amber, my true P.I.C., who looked past my “jovial” veneer and offered steadfast friendship; Scott, my brother-in-arms in the war against hegemony; Amy, who reminds me that it is never a bad time to watch The Breakfast Club; and finally, reigning office queens Mariah and Ellie, or, more appropriately, Cat and Katniss. Thank you all.

Additionally, I would like to thank my family. My brothers, Billy and Benjamin, have provided me with unconditional love and support. My mother, Angela, the strongest person I know, always reminds me that she has faith in me, even when I do not myself.

Finally, I dedicate this thesis to my father, Walt. Hooked on Phonics may have been 22 years ago, but it seems like it was yesterday that I learned that "dam" is not a bad word. I will never forget that you were my first teacher, and I am always grateful. 


\section{CONTENTS}

Page

ACKNOWLEDGEMENTS $\quad$ i

CONTENTS

\section{CHAPTER}

I. INTRODUCTION AND STATEMENT OF THE PROBLEM 1

II. REVIEW OF LITERATURE 9

$\begin{array}{ll}\text { Ideology } & 10\end{array}$

Ideology, Elites, and the State $\quad 11$

Ideology in the Contemporary Age $\quad 14$

$\begin{array}{ll}\text { Social Class } & 15\end{array}$

$\begin{array}{ll}\text { Gramscian Thought } & 15\end{array}$

$\begin{array}{ll}\text { Social Transformation } & 18\end{array}$

$\begin{array}{ll}\text { Gramsci and Ideology } & 20\end{array}$

$\begin{array}{ll}\text { Framing } & 21\end{array}$

$\begin{array}{ll}\text { Critical Framing } & 23\end{array}$

Critical Framing and Class $\quad 25$

$\begin{array}{ll}\text { Crime } & 28\end{array}$

$\begin{array}{ll}\text { Crime and Ideology } & 28\end{array}$

$\begin{array}{ll}\text { Crime and Class } & 30\end{array}$

Crime, Class, and Media Studies 31

$\begin{array}{ll}\text { Rhetoric } & 34\end{array}$ 
Rhetoric and Ideology

Ideographs

Rhetoric and Framing

Rhetoric, Crime, and Deviance

Conclusion

III. METHODOLOGY

Description of the Text

Detroit Demographic Information 48

Detroit Crime Statistics

49

Text Selection

Theoretical Framework

54

Data Analysis

Ideographic Analysis

57

Critical Framing Analysis

Procedure for Analysis

Conclusion

IV. ANALYSIS

Ideographic Analysis

$<$ Crime $>$

$<$ Bankruptcy $>$

70

$<$ Homeless $>$

74

Cluster Analysis

Critical Framing Analysis

Implicit References to <Poverty> $\quad 82$

The Poor as Antagonists

The Non-Poor as Victims

The Non-Poor as Saviors

Explication of Violence

100

Law as Benevolent

102 
$\begin{array}{ll}\text { Cross-Referential Analysis } & 105\end{array}$

$<$ Crime $>$ and Stigmatization $\quad 106$

$\begin{array}{ll}\text { Ideographs as Allusions to <Poverty> } & 108\end{array}$

$<$ Poverty $>$ and Causality $\quad 111$

$\begin{array}{ll}\text { Conclusion } & 114\end{array}$

V. CONCLUSIONS 116

Scholarly Implications $\quad 117$

Cultural Implications $\quad 121$

$\begin{array}{ll}\text { REFERENCES } & 125\end{array}$ 


\section{CHAPTER I}

\section{INTRODUCTION AND STATEMENT OF THE PROBLEM}

During the summer prior to beginning graduate school, I was visiting my home, which is in a small rural town in Northwest Ohio. While picking up some groceries for my father at a local supermarket, I came across two of my high school teachers in the midst of gossip. We greeted each other while I browsed the aisle near them, but they did not stop their conversation. I overheard one of them explaining that her cousin's family, who had just moved to the West side of our town a few weeks prior, had already suffered a burglary. With much vitriol, the second teacher responded, "Don't you read the paper? I don't know why you're surprised. That's what happens when a decent, hardworking family moves in with all the poor, lazy trash on the West side of town."

My family and I have lived on the West side of town my entire life.

At first, I was offended and potential retorts careened around in my mind. My thought process was something like: My family lives on the West side of town, too. We are not criminals. We are not trash, and we are not lazy. My parents work hard to make a decent living, and, while finances have always been tight, none of us ever wanted for anything. You should not lump all of us from the West side together and label us as likely criminals.

Moments later, however, I was ashamed. I realized that in my thinking about how offended I was by my former teacher's comment, I had engaged in precisely the same 
social logic that she had. I seized my standard definition of "criminal" and distinguished my family from it by pointing out our economic efforts and comparative financial achievement. Ultimately, even though my teacher was assertive, and I more subtle in my thinking, we both seemed to cling to the same essentializing assumption: Moral decency directly correlates with social class, and as such, those with less money are more likely to be criminals.

Obviously, this overgeneralization is not true. There are many decent members of society who belong to lower social classes without resorting to crime. Further, there are many depraved upper-class individuals who do engage in criminal behavior - in fact, their crimes tend to have much further-reaching consequences than the crimes of lowerclass offenders (Michalowski, 2009). Moreover, Perez (2010) asserts that, socioeconomic status aside, $91 \%$ of citizens in the U.S. commit a crime every year that, at minimum, is worthy of a sentence of jail time. Of course then, this reality begs the question of why people in our culture, like my former teacher and myself, possess that belief. Moreover, it is also important to consider the potential implications of that belief.

In this thesis, I will argue that the news media use pervasive descriptive themes to characterize criminality as a lower-class phenomenon, and that these themes are rhetorically capable of indoctrinating citizens into accepting this classist belief as truth. By utilizing Gramsci’s (1971) theories concerning cultural hegemony, I will assert that the internalization of these assumptions on the part of consumers allows them to demonize those belonging to lower social classes, thereby reinforcing cultural logics that justify the social prestige of wealthy elites. 
To perform my investigation, I will couple the methods of critical framing analysis and ideographic analysis to expose covert rhetorical messages within news coverage of crime within Detroit, Michigan. Detroit owns the distinction of being the largest city in Michigan (U.S. Census Bureau, 2013). Nicknamed the "Motor City" due to its global reputation for automobile manufacturing, Detroit enjoyed a position as a locus for industrialization and economic accomplishment in the early $20^{\text {th }}$ century. However, as happened in many major industrial U.S. cities, Detroit's population began to dwindle after the 1950s, resulting in the gradual abandonment of many city structures in the latter half of the century. As automobile manufacturing companies merged, jobs were lost and the city began to suffer from economic decline (Angelova, 2012).

Unfortunately, this escalated dramatically with the dawn of the new millennium. The automotive industry collapsed, and the city's residents plunged into poverty. Job markets decentralized rapidly, and residents began to leave Detroit in greater numbers (Ghallager, 2013). Abandoned buildings have resulted in plummeting property values, and the city's infrastructure began to crumble. Detroit rapidly garnered debt, culminating in its filing for bankruptcy on July 18, 2013. It is the largest city in U.S. history ever to have done this. Due to Detroit's accumulation of $\$ 18$ billion in debt, U.S. federal judge Steven Rhodes officially declared the city bankrupt on December 3, 2013 (Lichterman \& Woodall, 2013).

Detroit's widely publicized decline has not only been discussed in economic terms, but social terms as well. Specifically, it is often characterized as a crime capital of the country. Indeed, even though crime rates in Detroit declined in 2013, Forbes still 
ranked the city as the most dangerous in the United States due to its comparatively high levels of violent and property crime (Fisher, 2013). This marked the fifth year in a row that the city earned this rank.

Clearly, given the current conditions of the city in terms of both criminal behavior and economics, an analysis of how the relationship between these two social forces in Detroit is portrayed in mass media is both timely and culturally pertinent. In the remainder of this chapter, I will explain why this topic warrants our consideration, particularly from the angle of rhetorical criticism. To do so, I will offer definitions of crime and deviance and discuss how social understandings of criminals are conveyed through rhetoric. Finally, I will describe the impacts of the acceptance of these social understandings as truth by society at large.

Crime is a difficult concept to define without first addressing the idea of social deviance. Wonders (2009) explains that members of a society tend to share ideas about how people in that society ought to think, behave, and live. These pervasively shared modes of thought, given salient meaning through widespread communication, are known as social norms. Social deviance, then, may be defined as an act of nonconformity to those understood social norms (Giddens, 2009). Acts of deviance are not always behaviors that defy law. For example, it may not be illegal to have an eating disorder, but exhibiting anorexic behavior is still perceived as problematic by society because it is not a "normal" way of acting. Becker (1963) suggests that those whose behavior does not sufficiently conform to societal expectations are categorized as "social deviants" and are therefore treated as though they are inferior people. 
Thus, it follows that crime is a sort of "ultimate" act of social deviance. Crime is ultimate in the sense that it is a violation of a social norm that has received such a high degree of credence that it is literally codified into a society's guide of conduct (White \& Perrone, 2005). As Litowitz (2000) explains, the existence of laws is not inherent to society. Rather, laws are artificial codes of conduct, the creation of which is inspired by a dominant ideology that can then use legal code to demand that members of society conform to the expectations it propagates. Further, White and Perrone (2005) discuss that, although many acts of social deviance receive some sort of sanctioning, crimes are the only forms of social deviance that are explicitly identified and punished by a statecontrolled apparatus. The public nature of this punishment ensures that those who commit crimes are deemed to be deviants at the most extreme level, and thus, are subjected to the most extreme forms of control.

As explained previously, Wonders (2009) suggests that when like-minded individuals in culture construct social norms, meaningful identities are ascribed to those who conform to those social norms. However, Nielsen, Jones, and Perry (2009) suggest that those who differ from the norms established by society are ascribed identities that carry significantly more cultural weight. Even if one's "Other" identity is deemed to be negative, it is still more notable to members of society than the identity of another who successfully conforms because it does not seem ordinary. For example, in American culture, Whiteness is a social norm (Guess, 2006). In terms of racial identity, a Black person's race seems more salient than that of a White person, who is often considered to be racially neutral. Gould (2009) explains that those who possess differing, deviant 
identities are generally those represented in news and popular culture as criminals as well. He states "the term 'crime' is synonymous with 'minority crime'" (p. 33). These frequent depictions better enable conforming members of society to stigmatize those who do not belong, and thus function as rhetorical mechanisms for the maintenance of static social castes.

Michalowski (2009) extends this idea more particularly to the concept of socioeconomic class. The class status of one who is extremely poor or extremely wealthy is a more potent characteristic of identity than for a member of the middle class. Interestingly though, only the difference of those who belong to the lower-classes is regarded with widespread negativity. This is because social class, which has to do with one's acquisition of wealth, is socially treated as an at least somewhat controllable trait, whereas one's race or sex is not controllable. Therefore, the deviance from social norms displayed by the poor seems to be a result of laziness, and thus is often stigmatized at a grander level than uncontrollable forms of deviance such as sex. Michalowski argues that in no instances is this phenomenon truer than in the criminal justice system, which targets lower-classes to a massively disproportionate degree, or in media coverage of crimes, which portrays the poor as genuine offenders while characterizing the few wealthy criminals represented as social exceptions. Unsurprisingly then, crime in poor neighborhoods is treated with a "business as usual" mentality that perpetuates very harmful stereotypes, while crimes committed by the rich are either treated with surprise or go virtually unacknowledged. 
I will note here that I by no means support engaging in criminal behavior. I also am not opposed to the enforcement of the law, or to the news coverage of crime in a general sense. Rather, my argument is simply that the methods by which news outlets report crime are premised with classist assumptions. It is vital that we examine current articulations of difference in regards to such socially potent matters as crime, so that problematic and harmful rhetorics be exposed and challenged. This is especially necessary for those that occur in the form of news as opposed to other popular media, like movies and video games. Not only are news articles consumed on a massive basis like other media, but they are also perceived by its audience members to be objective sources of social truth (Gramsci, 2012). As a result, the rhetorical messages function in a covert manner, making consumers of these media susceptible to influence without their own realization that they are being persuaded. This surreptitious dissemination of messages regarding morality and identity is a powerful tool by which an ideology may reify the statuses of social elites, such as the wealthy and politically powerful. Ultimately, these messages act as a justification for power hierarchies in society. They inform audiences that those particular groups forced to the margins of the social sphere are morally deserving of that position.

Gramsci (1971) referred to this dominance as hegemony, and as previously stated, I will use his cultural critique to guide my own work in this thesis. As I will demonstrate in the next chapter, little scholarly work has been performed in an effort to link problematic representations of marginalized groups within the news media to overarching systems of cultural hegemony, and most of that work pertains to negative illustrations of 
gender and racial minorities as opposed to representatives of lower-classes. Thus, additional research must be done to unveil any potential means of oppressive social control.

In the chapters that follow, I will establish the necessity for my thesis within communication academia. Specifically, in Chapter II, I offer a review of literature to establish the critical theories that guide my analysis, as well as highlight the dearth of scholarship pertaining to the power relations espoused by media coverage of class and crime. In Chapter III, I provide a rationale for my choice of Detroit as a locus of crime news coverage, as well as a more detailed description of the texts I analyze. Further, I will explain the methodology of critical framing and ideographic analysis with which I examine those news articles. Chapter IV marks the beginning of the analysis portion of my thesis. The themes I am able to uncover from within my news articles about Detroit are identified and explained. I also present numerous examples of the themes from my texts. The social implications of those themes, as well as the rhetorical implications of my method, are discussed more thoroughly in Chapter V. 


\section{CHAPTER II}

\section{REVIEW OF LITERATURE}

In the previous chapter, I discussed the social phenomenon of crime, and described how misleading representations within media of those who engage in criminal behavior can be problematic to people who belong to groups marked by difference. Due to my own experiences growing up in a neighborhood often regarded as "at risk" by others due to its comparatively low level of wealth, I find myself drawn to challenging these generalizing illustrations of the poor as deviants from the law. If we do not search for such essentializing depictions of criminals and urge for more appropriate characterizations, we enable classism to persist in our culture.

I aim in this chapter to construct the theoretical framework that will provide the basis for the analysis I conduct for this thesis. To do so, I review literature pertinent to the concepts of ideology and social class, particularly focusing on the arguments of NeoMarxists such as Antonio Gramsci, as well as framing research, crime studies, and rhetoric. I also establish a need for my particular research to be performed by demonstrating clear gaps in scholarship on the subjects of news frames and representations of class and crime within mass media. Finally, I explore the connections between these various concepts by highlighting their relationship to rhetoric. 


\section{Ideology}

The term "ideology" is often problematic to define, not only because it refers to abstract concepts, but also because the term has been used in several different ways in academia. For example, Marx (1990) originally describes ideology as a set of social and political beliefs that dominate other beliefs in a society. In other works, however, Marx and Engels (1987) use the term to refer to insidious political lies used by elites to coerce their subordinates into a state of false class consciousness. For my purposes in this thesis, I use a basic yet clear definition of the term provided by many scholars. An ideology is a sort of shared mental framework used by members of a group to understand and evaluate their culture, culminating in a set of social values (Cormack, 1992; Foss, 2009; Hall, 1986; Hollihan \& Riley, 1993; Makus, 1990; Therborn, 1978; Thompson, 1990). This framework consists of a knowledge and acceptance of particular representations, upon whose deployment those people rely in order to define the structures that constitute their common social order. Indeed, the tenets of an ideology are treated as truths by those that accept them.

The definition I have chosen is distinct from the first Marxist definition provided in the above paragraph because it allows for the possibility of multiple ideologies to exist in a society at once. These ideologies often compete or are mutually exclusive. Naturally, then, some groups will favor certain ideologies over others. Further, given that these frameworks result in the manifestation of belief systems, certain behaviors and traits expressed by people tend to be valued more than others. This thinking can lead to the creation of a caste system, in which the social standings of different groups of people are 
hierarchically arranged based upon their levels of conformity to the values upheld by a dominant ideology.

Ideology, Elites, and the State. Many academics assert that, often, the ideological frameworks that take precedence in a society are those espoused by the state. Indeed, states often rely on various channels of control and persuasion in order to promote ideologies that best encourage their citizens to support their rule. One of the most popular among these scholars is Althusser (1971). Althusser believed that state apparatuses of power could be divided into two categories: repressive state apparatuses and ideological state apparatuses. Repressive state apparatuses are more obvious forms of state power that correspond with Marxist conceptions of overt coercion through violence and economic force. Examples of such structures include police forces, the military, and any administrative agencies within government. Clearly, these structures are concrete examples of state force exhibited through materiality.

Conversely, ideological state apparatuses are much more furtive in their operation. Repressive state apparatuses overtly force citizens to comply with social expectations, or otherwise punish them for their failure to comply. Ideological state apparatuses, however, operate much more covertly because they seek to control citizens through persuasion and indoctrination, and as a result rely upon their ability to construct social expectations that are much more implicit. Examples of ideological state apparatuses include family systems, political parties, schools, and churches. Such structures seem to exist to allow for the betterment of the lives of subordinates, but Althusser (1971) argued that in reality, they are merely means through which states may 
surreptitiously disseminate ideological teachings. Further, it is notable that while repressive state apparatuses punish nonconformists through physical or economic materiality, ideological state apparatuses encourage the stigmatization of nonconformists in society, which results in their loss of social status.

Gouldner (1982) explains that because states possess such powerful capabilities to create and endorse particular ideological beliefs, they often use ideology as a weapon of social order. Social elites who control state structures have the ability to promote the social beliefs best suited to maintaining the power of the government and its benefactors. Of course, if it is noticed that members of society who do not behave in ways that support the state's chosen ideology are able to reject conformity without consequence, cultural acceptance of the state's power may be diminished. To prevent this, states use their authority to sanction these nonconformists so as both to end present transgressions and to deter those that may occur in the future. White and Perrone (2005) go as far as to characterize these state sanctions as acts of violence. However, given that the social norms most widely accepted in societies tend to uphold the power of the state, this violence is perceived as both legitimate and necessary. As will be discussed later in this chapter, this greatly corresponds with arguments made by Gramsci (1971), whose approach I will use as a theoretical basis for my analysis.

It is also important to note that states that control the dominant ideology of their society possess another tool at their disposal in the face of ideological opposition: cooption. Therborn (1978) explains that within societies that are ruled by elites who control economic conditions, those elites often act in ways that seem to grant their 
opposition's desires, but really serve to diffuse the risk of opposition and preserve the status of the state. For example, Therborn explains that when groups of engineers began to outspokenly combat Soviet policies, the state responded by implementing policies of extreme economic expansion that offered direct financial benefits to such workers. While it may seem as though the engineers earned the upper-hand on a surface level, the Soviet state was able to swiftly quash ideological resistance with this strategy while both enhancing its own economic status as well as appearing to address the concerns of subordinate citizens.

Clearly, the conflation of state structures and culturally potent ideologies is powerful. Other scholars, however, differ from those discussed above and argue that dominant ideologies are so deeply ingrained within all members of a society that even elites, such as the wealthy or state representatives, internalize these social expectations and abide by the social logics promoted by those ideologies rather than directly controlling ideology to manipulate the lower class (Hall, 1982; Makus, 1990; McGee, 1980a1980b). Indeed, they are unaware of the nature of their power and privilege, and behave strictly as expected by the rules of their culture. Further, given both their acceptance of these ideologies as natural, as well as the fact that the ideologies have enabled them to achieve social positions of power and influence, elites are likely to maintain the functioning of these ideologies in their society. They can do so by continuing to rely on ideological formations in discourse, as well as by further implementing the ideology into social structures like the state. As a result, a dominant ideology can dictate the modes of thinking and behaving that are considered acceptable in 
a society. In this way, the state functions as a weapon of ideology, rather than ideology functioning as a weapon of the state.

Ideology in the Contemporary Age. As societies and their technologies have evolved, so too have the means by which ideologies may be disseminated to citizens and exchanged among them. This advancement is of particular concern to Thompson (1990). Thompson argues in favor of a new appropriation of ideological analysis to accommodate for mechanisms that allow for mass communication, such as the rapid spread of electronic media and the enhanced ability of individuals to interact with others efficiently, resulting in the opportunities for proponents of ideologies to advocate their views to larger audiences. This focus marks a notable shift in the study of ideology. While more traditional theorists like Althusser (1971) and Marx (1990) place more focus upon the implications of ideology and instances in which it is produced, Thompson (1990) asserts that greater attention ought to be paid to the mechanisms that create and maintain it as well.

As a result of Thompson's (1990) work, more scholarship began to examine processes of ideological construction based in mass communication, such as journalism. For example, Cormack (1992) writes extensively about news coverage regarding the fall of the Berlin Wall. His investigation of newsprint as an instrument of ideological advocacy allows him to make assertions regarding the ability of journalism to build greater unification among larger, more diverse audiences. Cormack argues that this form of mass communication enables the spread of ideological views to be more effective. 


\section{Social Class}

Although the correlation between possession of wealth and the possession of power has been demonstrated in several different cultures throughout history, perhaps the most important discussion of class began with Karl Marx during the Industrial Revolution in the 1800s. Marx (1990) critiqued the relationship between factory owners and factory workers. He felt that a capitalist economic system allowed an upper-class who owned the means of production (the bourgeoisie) to dominate and oppress a lower-class that was forced to labor for meager earnings (the proletariat). According to Marx, a societal value on access to capital allowed undue privilege for the factory owners who performed little labor and lived in luxury, especially in terms of their unhealthy and even violent relationships with their workers. Marx despised this oppression and indicated that a class revolution was inevitable. Marx's argument has been used extensively in academia, and whether or not they believe that power relations in society are entirely predicated upon elites' direct control over finances, many scholars feel that classist notions about an inherent superiority of the wealthy are a symptom of social hierarchies still present in contemporary society (Brantley, Frost, Pfeffer, Buccigrossi, \& Robinson, 2003).

Gramscian Thought. Marxist literature has fueled the generation of several other critical theorists concerned with social castes, many of whom are referred to as "NeoMarxists." One of the most influential among them is Antonio Gramsci. Gramsci's (1971) central argument differs from that of Marx in a very important way. While Marx asserts that elite groups in a society are able to achieve dominance through control over finances, production, and labor, Gramsci explains that the phenomenon is both grander 
and more insidious. He suggests that one's dominance is obtained and maintained through control over that society's most pervasive moral codes and cultural norms. Fontana (2005) explains that dominant groups construct these ideas of culture and morality, and surreptitiously disseminate them to the mass public through cultural structures they control, such as churches, schools, the criminal justice system, and the media - in other words, Althusser's (1971) examples of ideological state apparatuses. Gramsci (1971) explains that elites can concentrate themselves and the ideologies they espouse in the form of state apparatuses, which have obvious access to or influence over these social institutions. The result is a state-based superstructure relying primarily on soft cultural control, distinct from Marx's notion of blatant financial coercion.

I must here acknowledge that the concept of finance is still relevant. Mann (2013) explains that often, social elites are in a position to manipulate these structures due to their economic privilege. However, it is not control over economic conditions themselves that creates the possibility for their dominance. The propensity for this power is often more political than purely economic in nature. Indeed, Mann (2008) suggests that the possession of robust wealth is a symptom of real power, and may be used as a tool to exercise it.

Gramsci (1971) argues that the subordinate public generally accepts these disseminated ideas as truth. This large-scale acceptance of the same ideas as societal truths results in the manifestation of a cultural ideology: social concepts that, while artificial in nature, are treated as normal by those who participate in those social systems. These codes and norms function as active assumptions held by the society at large, and 
those assumptions generally dictate individuals" ways of understanding social "realities" and behaving within them. Gramsci describes these assumptions as instances of "common sense," as they are shared on a large scale and thus inform social meanings and relationships across entire societies.

In her discussion of Gramsci, Smith (2010) explains that these moral codes are likely to favor certain groups over others; after all, it is unlikely that elites would herald and reinforce ideology that would seem to indict or undermine their positions of dominance. As such, social castes tend to exist, ranked in a manner that suggests the degree to which they adhere to cultural norms. The resulting hierarchical social structures based upon cultural hegemony tend to exclude and often abuse those forced to the bottom of the caste system. Gramsci (1971) labels those who are marginalized in this way as "subalterns." One might consider the subaltern to be the parallel in Gramscian cultural theory to Marx's conception of the proletariat. In this way, members of societies find themselves divided into social classes.

The acceptance of social norms has a tremendous cultural impact. These expectations create a social context in which the members of those subordinate groups accept their dominance as normal or justified, resulting in hegemony. It is of particular importance to note this concept of acceptance of, or even what Zompetti (1997) describes as a "desire" for, these systems of domination (p. 73). Indeed, given the small numbers of the elite and the vast number of those placed in subordinate positions, it would seem that most instances of resistance against social control could be at least moderately beneficial. However, resistance against the hegemons in a society tends not to occur (at least not 
effectively) due to the internalization process described in the previous paragraph. Zompetti explains that the cultural systems touted by dominant ideologies both characterize themselves as exceedingly beneficial for all of those who conform to them, and also as dangerous for all of those who do not behave in accordance with social norms. By offering soft incentives for the conformists and posing threats of punishment against the rebellious, hegemons are able to inspire consent on the part of their subordinates, who feel that it is comparatively advantageous to remain within the social system as opposed to resisting it or finding a social location outside of it.

Social Transformation. To explain more particularly the social conditions that allow the subaltern to fall victim to the systems of domination created by hegemonic ideologies, Zompetti (1997) explains Gramsci's notion of the historical bloc. The historical bloc is a specific moment in time at which social conditions have allowed various groups and identities to be placed in a position of relative unity and equality. However, one group among the masses possesses a specific advantage that might allow its members to attain dominance under the guise of assisting the greater good. In this moment, other groups become vulnerable to the rhetoric of this particular group, and the messages its members convey about the status of the society as a whole begin to be accepted as social truths, assumptions that come to constitute common sense and ultimately, a pervasive cultural ideology.

For example, in the midst of economic stagnation, all groups in a society suffer to some degree and thus seem to share a sense of unity. However, in such a condition, people in positions of relative power, such as bankers, possess an advantage. While 
claiming to provide a service to society and to those who are suffering financially, banks can issue loans with exceedingly high interest rates to the poor who have no other options but to accept them. The construction of such a relationship allows the bankers to portray themselves as benevolent while they accrue wealth at the expense of the subaltern. Because it seems no other options exist, the subaltern are willing to accept such a relationship. Ultimately, positions of social hierarchy are born. Zompetti (1997) provides a similar example regarding the issuing of credit cards, which allow companies to seemingly offer the disadvantaged a chance to achieve the "American Dream," a commonly shared social myth that encourages the subaltern to continue to participate in the capitalist system to the ultimate benefit of those in power. After providing this example, Zompetti clarifies that historical blocs are not always as rigid as these examples may make them seem; rather, the occurrence of multiple historical blocs in a society over time demonstrates that power relations and systems of domination are not static; just as the social norms that create them are artificial, so too are positions of the hegemons. It is possible for the subaltern to unite in resistance and diminish the control of those in power.

Indeed, there are mechanisms by which the subaltern can engage in what Zompetti (1997) describes as transformative activity in order to resist the oppression inflicted by the hegemonic ideologies. Gramsci (1971) claims that the subaltern are capable of critically evaluating their positions in the social caste system, comprehending them, and acting against them. Finochiarro (1998) explains that this is a specific rejection of the notion that not all individuals can effectively engage with philosophical thought. 
While resistance is generally thwarted by common sense assumptions that prevail across society, Gramsci suggests that social revolution is possible if the public at large can critique social fabrications and, together, pursue a new method of understanding social relationships. Such a vast protest against the dominant cultural ideology is characterized by what Gramsci refers to as collective will; that is, a unification of the subaltern against the hegemony despite previously constructed differences between the various subaltern groups. This unification disrupts the problematic social assumptions previously described as "common sense" and allows the subaltern to achieve a new level of consciousness: good sense. Collective will can spur collective action against the elites, allowing for the construction of new systems of society and power relations.

Gramsci and Ideology. As ought to be clear at this point, ideology is a highly important concept in Gramsci's cultural critique; after all, the hegemons' ability to construct an ideology that justifies their social status and disseminate that ideology for wide acceptance by the citizens they dominate is their most powerful weapon. As such, it is important to note that a Gramscian approach to ideology is distinct from the conceptualization offered by Althusser (1971). As Therborn (1980) explains, Althusser is almost exclusively concerned with the task of identifying the actual structures that reproduce problematic social relations. Gramsci, however, is not a structuralist like Althusser, because he believes that mechanisms like the state are predicated upon ideology, as opposed to the predication of ideology upon the state. Gramsci notes that these instances of exploitative power must be considered in terms of hegemony; that is, we should not just examine the way that oppressive power is reproduced, but we must 
also investigate the patterns by which these reproductions consistently support a limited core of social elites. It is for this reason that Gramsci discusses the idea of "civil society" as a social location that enables ideologies to develop, disseminate, and configure cultural logics of common sense. Further, Gramsci is also concerned with evaluating eruptions of marginalization in terms of their historical contexts, whereas Therborn suggests that Althusser felt such flexes of power may be explored within the vacuum of their own occurrences. Ultimately, Therborn argues that Gramsci's approach to ideology is of greater benefit to understanding society.

Further, as Hawkes (2003) explains, while materiality may be a mechanism through which ideologies are disseminated, Gramscian thought does not consider materiality to be a component of ideology in and of itself. As such, for Gramsci's (1971)

purposes (as well as mine), ideology refers purely to social consciousness, suggesting that it is through these beliefs that we lend cultural meaning to materiality. This coincides with my preferred definition of ideology offered above, which suggests ideology is a shared framework of thought based upon widely accepted cultural beliefs as opposed to material conditions.

\section{Framing}

Though there are many definitions of framing, perhaps the most thorough and applicable to my study is that proposed by Nelson, Oxley, and Clawson (1997). Nelson et al. define "framing" as "the process by which a source defines the essential problem underlying a particular social or political issue and outlines a set of considerations purportedly relevant to that issue" (p. 222). The concept of framing came about in the 
1970s through the writings of Goffman (1974), who suggests that journalists tend to characterize information they report with particular themes and conventions known as "frames." These themes and conventions reflect those relevant considerations explained by Nelson et al. (1997). Further, Iyengar $(1987,1989,1991)$ suggests that there are two general categories of frames: episodic frames and thematic frames. Episodic frames, which are much more common, are those that discuss issues and events in terms of very particular instances. Thematic frames, on the other hand, describe issues in a generalized or abstract way.

When the news is consumed by an audience, those frames are consumed along with the information presented in the articles, and thus affect how the members of the audience evaluate the contents of the news. Therefore, frames present within news that are pervasively used by journalists, and thus are repetitively internalized by consumers, must have a notable influence on the creation of social expectations. D'Angelo (2002) characterizes this view of news frames as a "constructionist approach" (p. 878), because it explains how the public comes to share conceptions of social and political events without necessarily interacting with one another.

In much research, however, the focus of framing research has shifted from social construction to the cognitive effects of news frames upon audience members. Authors such as Scheufele (1999) emphasize examining the psychological processes by which the consumption of news frames may activate an audience's cognitive schemas, thus triggering pre-established thoughts. Iyengar and Kinder (1987) discuss a phenomenon similar to framing, and agree that media structure their messages in ways that, in some 
form, characterize news items. However, Iyengar and Kinder hypothesize that in addition to defining the relevant issues of news items in their coverage, media also encourage audiences to adopt particular moral standards to evaluate those issues. They referred to this idea as "priming." While such research may be helpful in understanding the means by which frames influence audiences from a scientific perspective, it fails to consider both the social ramifications of audience members relying upon these schemas in terms of the maintenance of dominant ideologies, as well the cultural contexts in which the frames were deployed in the first place.

Critical Framing. D'Angelo (2002) also explains a third perspective of framing research, to which he refers as the critical approach. A critical framing scholar would agree with the constructionist view of framing that prevalent themes result in widespread social expectations. However, critical framing research argues that these frames construct socially oppressive norms and meanings that reify dominant ideologies, thereby offering justification for the positions of an elite, power-wielding few.

The concept of critical framing was originated by Tuchman (1978), who challenges Goffman for not critiquing the institutions that construct news frames. Despite Tuchman's best efforts, however, there is still a dearth of critical framing research in scholarship. Still, many academics have appealed for further analysis of the dominant ideology inherent within pervasive news frames, as well as a critique of the institutions that produce them. For example, Holstein (2003) asserts that the themes presented in the news media function on a rhetorical level by spreading messages that support a hegemonic ideology. Consumers of the news internalize these messages, enabling the 
maintenance of dominant power structures in society. Further, she suggests a technique by which critical scholars may begin evaluating the implications of news frames. Holstein indicates that most framing studies only analyze antecedent statements within news articles, divorcing them from the overall context of the article in which they were included. Instead, she argues that the article in its entirety ought to be qualitatively analyzed, so that there be no risk that context is nullified. Such an assertion encourages the analysis of the rhetorical situation of the frames so that critics may evaluate which frames news-making institutions feel are most appropriate for which situations.

Similarly, Carragee and Roefs (2004) assert that news research has placed too great of an emphasis on examining the cognitive effects of consuming media. These social scientific studies are problematic because their methods and results remove isolated pieces of content from a level of greater contextualization as they are presented within media and, thus, from the context of social norms and cultural power. In particular, Carragee and Roefs discuss the concepts proposed by Gramsci (1971) who argues that ideologies maintain dominance through their perpetuation through social structures like the media. These structures disseminate morally charged ideological rhetoric designed to be consumed and internalized by the mass public. Carragee and Roefs (2004) express their hopes that more academics will perform critical framing research because they feel that such rhetorical scholarship is an important means of identifying oppressive power structures within sources people feel to be objective and truthful. 
Critical Framing and Class. Surprisingly, critical framing studies in regard to the representation of class in the news media have not been extensively performed in the communication field. Still, a nigh-comprehensive overview of class frames in the mass media, including sources from both news and popular culture, was released by Kendall (2011). Kendall explains many of the pervasive themes and narratives used by the media to characterize each of the social classes, using multiple examples throughout history to make her case. Further, she explains that these frames generally reify capitalist assumptions that members of upper-classes are superior to lower-classes, and that those at the bottom of the social hierarchy behave in opposition to social norms and should be stigmatized in some fashion. Kendall ultimately asserts that these pervasive characterizations of social class do result in the construction of an oppressive social reality shared amongst media consumers, who constitute the bulk of society. This is particularly true in the case of news media, which, as Gramsci (1971) explains, is generally perceived to offer information in a way that is truthful and value-free. As such, Kendall argues for a rearticulation of class portrayals in the media.

While Kendall's (2011) analysis is exceptionally thorough across the class spectrum, it does have some shortcomings as well. Although she obviously problematizes social class relations and identifies media as a mechanism for their perpetuation, Kendall fails to explain this in terms of ideology. In other words, Kendall clearly indicts cultural oppression, but neglects the important discussion of the hegemonic forces that spawn it. Relatedly, her analysis only tangentially related to rhetoric at best and as such, does not 
explain the relationship between the manifestations of these classist beliefs and the political intent of the ideologies that spawn them.

Finally, it is notable that Kendall (2011) identifies the consolidation of media outlets into large-scale media monopolies as a source of such problematic representations. The extreme concentration of several outlets within very few parent companies grants control over mainstream media messages to a small handful of wealthy corporate tycoons and influential politicians that Kendall argues have a strong interest in obfuscating the public's understanding of class. It could be true that, as Kendall implies, these elites manipulate media portrayals of class to perpetuate the economic hierarchies from which they benefit. However, I prefer the relationship between ideological power and social elites that is described by Hall (1986) and McGee (1908b): Even the thoughts and actions of elites are driven by their acceptance of a dominant ideology - they just happen to be in a position to reap the social benefits. Therefore, it is more productive to challenge the ideology that creates power disparities rather than the socially privileged that benefit from it.

Another framing study of class was conducted by Entman and Rojecki (2000), who performed a content analysis of several hundred news articles and broadcasts. The authors' analysis of class structure contains many of the same problems as Kendall's (2011) book. Entman and Rojecki (2000) are clearly concerned with the consequences of social power disparities, but they do approach their project from a quantitative perspective rather than with a rhetorical or even a qualitative approach; as such, the observed instances of framing they discuss in this chapter are, as Holstein (2003) writes, 
divorced from the overall contexts of the news stories, precluding a more thorough understanding of how hegemonic ideology may be present in the form of overarching themes of content. Relatedly, like Kendall (2011), Entman and Rojecki (2000) do not explicitly connect the problems they observe in the news media to the idea of an undergirding ideology. Finally, while their focus is certainly both admirable and necessary, these authors were more concerned with the racial implications of news stories pertaining to poverty, rather than the classist implications themselves.

Despite these shortcomings, Entman and Rojecki's (2000) analysis still offers great insight as to how class relationships are depicted in the news. For example, they found that news stories involving poverty frequently characterized the activities of the poor either as threats to the physical and emotional well-beings of non-poor people, or else as affronts to the more "moral" way of life that members of wealthier social classes are illustrated to be upholding. Additionally, Entman and Rojecki assert that poverty is quite rarely a topic that is explicitly discussed in the news. Instead, anchors and journalists tend to use two methods to broach the subject. First, news stories hint to their audiences that class is relevant to the subject by using verbal descriptors that are stereotypically indicative of conditions of poverty, such as referring to poor areas as "tough neighborhoods." Second, news media avoid the need to directly address poverty as a social condition by instead issuing stories that discuss the various symptoms of it most frequently, crime. Entman and Rojecki ultimately suggest that this implicit treatment of poverty in the news can enable the construction and perpetuation of the 
social beliefs, particularly among middle and upper classes, that the poor are lesser beings that are responsible for their own lack of social standing.

\section{Crime}

In the previous chapter, I established definitions of crime and social deviance found in scholarship. Ultimately, a state's creation and dissemination of a legal code to its citizens creates cultural beliefs that are firm and pervasive regarding the behaviors that are necessary to avoid if one wishes to behave decently and act as an asset to society. The establishment of laws that normalize actions necessarily create a general dichotomy of behavior: conformity and crime.

Crime and Ideology. As explained previously, Gramsci (1971) writes that hegemonic ideologies inculcate the mass public with oppressive social meanings through a variety of institutions and social structures. Certainly then, these apparatuses are sources of powerful rhetorical messages. Although all these structures are important and merit extensive analysis, I am concerned with just two of them for the purposes of my thesis. The first is the notion of law. According to Gramsci (1971), the state seeks to create particular types of societies, as well as members of those societies, via the encouragement of certain types of relationships and behaviors while vehemently discouraging others. The mechanism by which states engage in this regulation of behavior is the creation and enforcement of law. He writes, "If every state tends to create and maintain a certain type of civilisation and of citizen (and hence collective life and of individual relations) and to eliminate certain customs and attitudes and to disseminate others, then the Law will be its instrument for this purpose" (p. 246). Gramsci indicates 
that the law is an inherently repressive social construct; because its sole existence is to demonize particular activities and punish those who engage in them, legal exercise is the negative underbelly of a state that, on the surface, is seemingly constructing a beneficent society. This is not necessarily an indication that law and the exercise thereof are problematic; rather, Gramsci critiques the methods by which the state executes its legal code. The state is determined to act as an authoritarian educator and thus involves itself as a party in all instances of criminal violation. An example of this may be seen in the United States legal system. When an individual is on trial for criminal behavior, the prosecution is said to be representing the state rather than the people of society or, more appropriately, the victims of the criminal behavior in question. In this way, the state purports itself as the true victim of the crime and thus the entity most deserving of reparations. Further, policies such as these characterize the state as the champion of civil behavior and of morality, and thus serve to further reify the state as the bastion of appropriate social behavior.

Litowitz (2000) analyzes the implications of contemporary legal code in the context of Gramsci's arguments regarding the law and the state. He argues that the law certainly does operate as a mechanism of hegemonic control, and that this mechanism is both able to surreptitiously perpetuate certain notions of relative social morality as well as to earn the tacit consent of the people in a society. While Litowitz largely corroborates Gramsci's claims, he also argues that Gramsci's description of class as a totalizing cause of hegemony is not totally accurate. He asserts that dominant classes do not influence legal codes to result in the oppression or exclusion of a marginalized class; rather, the 
moral map espoused by the codes themselves is the source of hegemony in law. I disagree with this argument for two reasons. First, as Litowitz himself indicates, legal codes are not inherent to a society. Rather, they are only written, reformed, or enforced after the people within a society have internalized an ideology and wish to establish it within social structure. Second, Litowitz concedes Gramsci's argument that the law is disproportionately used to sanction the most marginalized of the subaltern, as compared to members of society who more clearly align themselves and are supported by the dominant ideology. Despite these problems with Litowitz's conclusion, he still offers a useful discussion regarding the three ways that law functions in a hegemonic capacity: It excludes sources of morality other than that of a state structure predicated upon ideology, it socially constructs behaviors (and thus those that engage in them) as either acceptable or criminal, and finally, it encloses the processes of legality entirely within a statedesigned paradigm.

Crime and Class. Many scholars have investigated the relationship between social class and criminal behavior. In his text that surveys criminological theory, Siegel (2009) explains that most criminologists believe that the majority of criminal behavior is a result of classist oppression and, therefore, most criminological studies are driven by this belief. Essentially, they characterize most crime as a mechanism of competition over scarce, finite resources - essentially, a byproduct of Marxist notions of bourgeoisie dominance. For example, an incidence of burglary is not necessarily a malicious act so much as it is a means for the offender to acquire resources of money or goods. These criminologists, known as critical criminologists, argue that as the scarcity of resources 
increases, so does the propensity for crime. Crime is fundamentally a lower-class phenomenon from this perspective, as members of this class suffer from the greatest resource scarcity.

I find these theories to be problematic because crime is not predominately a lower-class phenomenon, despite media characterizations to the contrary. Granted, material conditions are indubitably linked to criminal behavior. Lower-class individuals may feel compelled to commit certain crimes, such as property violations or burglary, to a greater degree than members of upper-classes as a perceived financial necessity. However, as discussed in the previous chapter, Michalowski (2009) explains that crimes occur at all social levels of wealth and power, an argument corroborated by statistics provided by Perez (2010) that suggest the vast majority of all U.S. citizens commit crimes. Indeed, the crimes committed by the wealthy often have an impact on society that is significantly more detrimental. Theories such as critical criminology validate media representations of criminal behavior as a lower-class phenomenon, and in turn justify the demonization of those presumed likely to be criminals. The implication of this instance of common sense is the reinforcement of the idea that the dominance embedded in social hierarchy is not only natural, but also good.

Crime, Class, and Media Studies. Several scholars have performed critical framing analyses of crime, although it is often limited to discussions of cultural norms in relation to race and sometimes gender (Brown, 2003; Howitt, 1998; Katz, 1987; LeDuff, 2012; Lotz, 1991; Roach, 2012; Wykes, 2001). At best, these studies analyze media coverage of class on a tangential level. However, they do draw some important 
conclusions about the implications of media coverage and crime. All of these authors indicate that media frames do characterize crime and those that commit crimes in such an essentialist way that such characterizations result in widely held stereotypes about criminal offenders. This results in a culture in which it is deemed acceptable to consider certain people "criminals" based purely upon surface-level observations of them, thereby perpetuating stereotypes. Further, these authors assert that these occurrences are manifestations of an ideology that perpetuates a cultural hegemony - in this case, a domination of those deemed to be criminals. Unfortunately, while these studies are helpful in identifying instances in which hegemonic social control manifests itself, they ultimately fail to reflect on the processes by which hegemony is maintained or the cultural conditions that create the capability for hegemonic ideology to persist in the first place.

Despite this flaw, a few of these studies are helpful in understanding the greater societal representations of criminality. Members of society learn to connect marginalized people with criminal behavior and use these assumptions to stereotype them as criminals, thus casting them as deviant and immoral. Such an identity is difficult to escape. Second, Lotz (1991) contends that these perceptions affect policy as well; these perceptions extend as far as police business, encouraging officers to increase crackdowns on the individuals expected to commit crime. For an example in the context of social class, Michalowski (2009) argues that the police increase patrol presence in poor communities because they expect greater instances of crime. Reiman (1998) asserts that increased police crackdowns result in the discovery of more criminal behavior, resulting in arrest 
rates that are classist and disproportionately reflect instances of crime between lower classes and higher classes.

Two studies, however, warrant particular consideration. Stephenson-Burton (1995) discusses media portrayals of white collar crime. Ultimately, he concludes that discussions of white collar crime usually occur by discussing particular instances through episodic frames rather than using thematic frames to treat this deviant behavior as a general social phenomenon. Indeed, stories of white collar crime are presented as detailed narratives that captivate audiences. The public perceives them as interesting, unique social phenomena. Stephenson-Burton argues that this creates a binary relationship between crime committed by the upper-class and crime committed by the lower-classes. Specifically, if white collar crime is a rare phenomenon that warrants particularized coverage, then crime among lower-classes, which receives sweepingly general coverage, must be a normal and pervasive phenomenon. While I find this observation compelling, Stephenson-Burton does not analyze the ways that coverage of lower-class crime normalizes the incidents.

Potter and Kappeler (2012) offer some discussion of the influence of hegemony upon media coverage of crime performed by members of the lower-class. They explain that media representations of criminals reify classist stereotypes of criminals, primarily because news is largely considered to be unbiased. More interestingly, they argue that there is an overwhelming focus on the poor as criminal actors and the wealthy as their victims. Moreover, Potter and Kappeler indicate that these framings of class in a criminal context are tools of a hegemonic ideology that has entwined itself with both cultural 
beliefs and more concrete social structures. For example, the state's criminal justice system looks to the dominant ideology to define unacceptable behavior through law, and, further, journalism serves as a channel through which the ideology may communicate these norms to a mass audience within value-laden contexts.

While this analysis is insightful, I find it to be potentially problematic that the authors also assert that news media do not establish a link of causality between poverty and conditions that result in crime and instead rely entirely on representations to communicate the messages outlined above. I disagree and feel it is likely that, at least in recent news coverage of crime, journalists will establish causality between low social standing and conditions that allow for the existence of crime. If this is the case, it would also be possible that such reports will cause audiences who are not of the lower class to believe in this representation as reality. Should consumers accept that view as a truism, they could begin to reconfigure their expectations of the social world around the conception of poverty as a source of crime, thereby inciting apprehension or even fear of the poor. This process, known as acculturation, is an element of Gerbner's (1973) cultivation theory, which posits that individuals' understandings of the outside world are significantly shaped by snapshots of it provided by media. Given these potential implications, I will search for evidence of the journalists' establishment of a causal link between poverty and crime when performing my analysis.

\section{Rhetoric}

As with the term "ideology," the term "rhetoric" is difficult to define because it is used in many different contexts at varying degrees of abstraction. Keith and Lundberg 
(2008) explain that rhetoric is used to refer to any communication that is persuasive, from the style employed by a speaker offering a public address, to the analysis of how meanings may be exchanged through language or other symbols to accomplish tasks, or even to any language devoid of intellectual or valuable meaning. Although these are common ways to utilize the term, they are relatively informal and imprecise. For my aim to employ a Gramscian lens in this thesis, the most suitable definition of rhetoric is that supplied by McGee (1980a), who describes rhetoric to be nothing more or less than politically motivated attempts to persuade an audience, often through language and discourse. In this context, then, rhetoric is embedded within messages that espouse "social truths" so that citizens will accept those norms, conform to them, and stigmatize others who do not.

Now that I have established a definition of rhetoric for the purposes of this thesis, I will explain how rhetoric relates to the various other concepts explored in this chapter. The relationship between rhetoric and Gramsci's (1971) conceptualization of social hierarchy is already described above; however, it is necessary to discuss more specifically the construction of such coercive messages, as well as the social structures through which they are disseminated.

Rhetoric and Ideology. Several scholars argue that rhetoric is the means by which ideologies come to exist, become shared, reinforced, and sometimes changed (Foss, 2009; Hall, 1982; Makus, 1990; McGee, 1980a; McGee, 1980b; McKerrow, 1989; Railsback, 1983). Salient, pervasive rhetorical suggestions can be accepted as truth by members of society and, thus, can be treated as social realities and beliefs. When 
messages become sufficiently salient to majority of the society, their meanings are adopted as social norms and form dominant ideologies. Everyone is capable of issuing a rhetorical message, and, much like ideologies, rhetorical messages often contradict one another. However, certain rhetorics resonate with people more than others, whether due to the comparative power of their sources vis-a-vis the sources of competing messages, the frequency at which the messages are issued, or even the length of time that the meanings behind those messages have been accepted by society. It is these factors that allow certain ideologies to dominate others.

Moreover, as McGee (1980b) explains, once an ideology becomes dominant in a culture, the social thinking that is promoted by that ideology forms the basis for future rhetoric within the culture. In this way, the relationship between rhetoric and ideology is highly cyclical, in that one continuously reconfigures the other. Hall (1986) explains that people often think, communicate, or behave in ways that rhetorically endorse ideological beliefs, but do so unintentionally; indeed, people believe they are simply performing acts they perceive conform to a natural code of cultural expectations. The existence of an ideology is not so much dependent on the intentions of people to promote it, but rather, on its ability to root itself within the logics of socialization and rhetorically persist through discourse. Therefore, it is this phenomenon by which ideologies sustain themselves that requires us to conceive of rhetoric as politically driven, as opposed to the conscious social aims of people themselves. To understand this distinction, it may be helpful to think of ideology as a virus. Even though viruses are not sentient, living beings, and therefore do not have motivations, they still engage in processes to spread throughout 
populations and multiply themselves. If we think of rhetoric as such a process, we can see that ideology functions in much the same way.

Ideographs. According to McGee (1980a), messages intended to persuade audiences to either adopt or affirm belief in a particular ideology are able to do so because they subtly condition audiences to accept them rather than blatantly forcing them. This conditioning occurs through the rhetorical deployment of words and phrases that are powerfully salient to mass audiences on a cultural level, so much so that they serve to evoke citizens' own values. To illustrate this, McGee provides the example of the United States government attempting to convince its citizens that engaging in war is necessary in order to demonstrate bravery and protect freedom. Given the social and political origins of the American culture, words such as <bravery $>$ and <freedom> resonate strongly within many consumers of those messages, working to elicit potent emotions and values. Indeed, these words convey a symbolic meaning to many Americans that reaches far beyond their denotative definitions. McGee refers to such words and phrases as "ideographs" - terms that are inundated with so much cultural meaning that they enforce ideological beliefs. In order to visibly mark ideographs from other words and phrases in a text, McGee (1980a) and others (see Hamilton, 2012; Moore, 1997) set the ideograph off from other words by bracketing or carroting the words, such as "<ideograph>" instead of simply "ideograph."

McGee (1980a) further explains that the deployment of ideographs is a highly effective means of rhetorical influence because, often, those who receive the messages that contain them do not even realize that they aim to be persuasive. Again, we should 
consider McGee's example of a U.S. government campaigning for public war support. Initially, campaigns may seem overtly persuasive. However, because the necessity of proving the bravery of the nation and maintaining the freedom of its people have become such a cultural given, these persuasive messages no longer seem to function rhetorically at all. Instead, they simply seem to describe reality and as a result, citizens imbibe persuasive messages that concretize dominant ideologies without even realizing it and, more prominently, without the opportunity to challenge them.

In this way, McGee (1980a) advanced that these ideographs function as the very foundational elements of social ideology. This is because they come in the form of simple words and phrases that are commonly used, and people within a culture exchange them with one another in genuine discourse repeatedly. Many subsequent scholars have examined functions of ideographs that are used in this way as they pertain to the construction of political ideology. For example, Connelly (2012) performed a synchronic analysis of the often competing ideographs <privacy> and <national security> as they were used to contextualize a Foreign Intelligence Surveillance Court of Review legal opinion in a case postdating the $9 / 11$ attacks. He found that through the prioritization of <national security> over <privacy>, the FISCR was able to prioritize and justify an ideology favoring American exceptionalism over liberal individualism. Ideographs function as a means of creating and reforming religious ideology as well. BennettCarpenter and McCallion (2012) analyzed how the deployment of <new evangelization> by leaders of the Catholic Church spurred enthusiasm and activism amongst parishioners to find ways to negotiate the religion's commitment to tradition, but also manage the 
challenges accompanying interactions with secular government agencies as well as a socially liberalizing society.

Others have investigated the role played by ideographs in the construction of different aspects of social identity. For example, Palczewski (2005) discussed the antisuffragists' deployment of the ideographs $<$ man $>$ and $<$ woman $>$ during the campaign for women's suffrage in 1909. She focuses primarily on a postcard series that features decent, hardworking <men> suffering through domestic labor traditionally delegated to females, while villainous-looking <women> run amuck while voting, or otherwise engaging in masculine occupational roles. Palczewski concludes that these value-laden representations of reversed gender roles served to reinforce culturally traditional connotations of gender identity. Ideographs also function in a way that connects social identity to the political ideology of the state. Ewalt (2011) explains that through tying the ideograph $\langle$ heritage $\rangle$ with those of $\langle$ freedom $\rangle$, <independence $\rangle$, <liberty $\rangle$, the United States federal government has been able to isolate the residual colonialism of the Native American people by illustrating their "nations" as private and distinct from considerations of the public sphere. By marking the maintenance of American Indian nations and monuments a private instance of protecting <heritage >, the public government characterizes colonialism as a matter of the past.

Railsback (1983) uses the concept of ideographs as the basis of her bounded network theory of language. The bounded network theory of language asserts that ideographs are terms that espouse the richest ideals of a culture, but whose meanings depend on the public's interpretation of the relationship between material reality and the 
symbolic conditions in which they are used. Condit (1987) further develops the theory, asserting that ideographs' linkages between the ideal and reality are constituted by characterizations, or labels used to create culturally resounding identities, and narratives, which are stories shared in genuine discourse that demonstrate the relationships between different characterizations. Lucaites and Condit (1990) use this approach to examine the civil rights discourse of Malcolm X and Martin Luther King, Jr., arguing that the rhetoric of both advocates was effective because of the ways in which it used the ideograph $<$ equality> to alter cultural narratives, or else produce entirely new narratives.

Finally, it is notable that, because the additional meanings that ideographs herald are so exceedingly particular to the cultural and political contexts of a given society, the use of these words is a powerful mechanism to construct difference. As McGee (1980a) explains, one who does not belong to a culture will not feel compelled by the receipt of a message containing an ideograph, and this absence of resonance essentially isolates him or her from the opportunity to attain that identity. Ultimately, McGee argues the analysis of ideographs is a fruitful means by which scholars can begin to understand ideology. This investigative process will be discussed in greater detail in Chapter III.

Rhetoric and Framing. As Gramsci $(1971,2012)$ explains, the press is a tool through which ideology is deployed in the form of particular pieces of information that are issued to the public for political purposes. By "particular," I mean that certain issues are presented to media consumers at the expense of others, and that those issues are characterized in ways that are beneficial to the statuses of the elites supported by the dominant ideology. As such, newspapers and related media are rife with underlying 
moral propaganda. As this propaganda is designed to construct and calcify dominant cultural ideologies within the minds of their consumers, such as the subaltern or otherwise subordinate public, it serves an important rhetorical function. This mechanism of rhetoric is particularly effective in spreading ideology because news sources are often considered by people to be objective and divorced from values or biases. As a result, consumers often accept the particularized framing of the selected news issues as both important as well as true.

News frames may operate on a powerful rhetorical level by persuading audience members who read them to accept journalistic writing as true information, as well as to concretize or adopt particular ideological perspectives. For example, Benford and Snow (2000) suggest that in order to better ensure that their news stories resonate with audiences, journalists may use certain types of frames, known as master frames that evoke salient cultural themes from their readers. In using master frames, journalists reinforce the social beliefs upon which those cultural themes are based. As such, multiple citizens who consume the same culturally poignant news frames can begin to share similar social expectations. Benford and Snow go as far as to argue that frames can result in the construction of shared social identities and needs.

Benford and Snow (2000) additionally discuss that there are multiple types of frames that can be deployed to instigate social unity, and even sometimes action. For example, diagnostic frames identify social problems and attribute blame to some type of cause. Another type of frame, prognostic framing, proposes some type of solution to the problem, or else a strategy with which the problem may be collectively dealt. The third 
and last type of collective action frame, motivational framing, calls the collective audience together to engage in some sort of group action to deal with the problem. Additionally, Kaufman, Elliot, and Shmueli (2003) explain that there are also frames that work to persuade audiences that social conflicts cannot be solved. They refer to these frames as intractable conflict frames. Intractable conflict frames preclude the resolution of conflicts by portraying the forces within a particular social conflict as both mutually exclusive, yet mutually destructive.

Further, Snow, Rochford, Worden, and Benford (1986) identify some processes by which social movement organizations place frames in the media so that they are better able to connect individual desires with their own goals and thus, attain new members. This process is known as "frame alignment" (p. 464). Snow et al. explain that there are multiple types of frame alignment. For example, frame amplification functions by clarifying and emphasizing a particular issue in the news related to a social movement organization, so as to encourage individuals to seek out that social movement organization. Kahnemann and Tversky (1979) describe an additional type of frame alignment known as valence framing, which occurs when social movement organizations couch positive or negative issues within particularly salient cultural themes in order to more overtly influence the behaviors of external others.

Finally, the relationship between more critically-oriented framing scholarship and rhetoric is highly important. Kuypers (2010), who is perhaps the most prolific critical framing scholar, argues that frames coerce an unknowing public into viewing social and political issues in certain ways. He writes, "When highlighting some aspect of reality 
over other aspects, frames act to define problems, diagnose causes, make moral judgments, and suggest remedies" (p. 301). The presentation of such value-laden framings of issues within media that are expected by the mass public to be sources of unadulterated information allows for an unassuming mass public to consistently consume rhetorically powerful characterizations of societal problems that ultimately shape their views of society and their relationships with others.

I do not consider journalists, or even the institutions for which they work, to be forces that intentionally create and disseminate ideology, although some may. I recognize that I am incapable of understanding what socially motivated intentions, if any, are possessed by those who create the news. For the purposes of my thesis, I proceed with the same beliefs as Hall (1986) and McGee (1980b), who argue that the construction and perpetuation of ideology is not based upon people's intentions, but rather, the content of their discourse. I will consider the press in the same terms as Gramsci $(1971,2012)$ as well as the many critical framing scholars (Carragee \& Roefs, 2004; Holstein, 2003; Kuypers, 2010) who describe it as a mechanism through which an ideology may rhetorically proliferate itself to a mass audience. As such, any claims I make that critique the perception of news media as "objective" aim to challenge the moral neutrality of the content of their articles, as opposed to any political agendas their authors may possess.

Rhetoric, Crime, and Deviance. Being known by others in society to have deviated from social norms, or to have committed a crime, carries great rhetorical significance. This is best exemplified in Becker's (1963) labeling theory. Becker explains that tools of society, such as various media, use different descriptors to categorize people 
based on their behaviors. This categorization spreads through the majority of society, allowing for a general, consensual opinion to form regarding the subjects and their behaviors. Becker suggests that those whose behavior does not sufficiently conform to societal expectations are categorized as "social deviants" and thus treated as though they are inferior people. As explained in Chapter I, laws are widely considered to be ultimate social norms. As such, those who transgress from the law may be considered the ultimate deviants, and receive a label of corresponding severity: criminal. In social terms, the receipt of such a label is functional damnation. Becker argues that in further exacerbation of this outcome, should one receive a deviant label, he or she will internalize that label as an unavoidable aspect of his or her identity. In other words, people who are told they are criminals will begin to believe that they are criminal in nature, and will behave as such. Simply put, their deviance will become a self-fulfilling prophecy. Although Becker discusses this phenomenon in terms of instances in which an individual is actively treated as a criminal by others, it seems possible that one who sees within media the demonization of others with whom he or she somehow identifies and/or shares particular qualities may begin to believe that the same stigmatization applies to him or her.

Becker (1963) further explains that because labels of deviance are arbitrary, society at large does not consider them in terms of specific individuals. Rather, members of a culture think in generalizations about those likely to deserve a deviant label. In other words, they stereotype. This phenomenon is of particular concern to me because often when covering crime news, journalists do not refer to specific individuals as criminals; rather, they offer general references to groups of potential offenders based upon the 
sharing of a high-risk social characteristic, such as poverty (Gould, 2009). This

essentializes all poor people as likely criminals, regardless of whether or not they are genuine offenders. Labeling any one group, like members of a lower social class, as "criminal" results in the construction of a deviant identity that both prevents the members of that group from attaining a position of social acceptability while allowing other, more dominant groups to maintain a position squarely above the criminalized within the societal hierarchy of power.

After considering the literature herein discussed, three arguments may be made. First, dominant ideologies can be highly oppressive, as demonstrated by the artificial constructions of social class and the social assumptions that spring from them. Second, the need for critical framing research is profound enough for numerous academics to call for it within their own scholarship (Carragee \& Roefs, 2004; Holstein, 2003). Related to this point is the fact that there is no significant research in the field that attempts to connect ideographic analysis with critical framing work. Finally, there is a surprisingly significant dearth of research regarding news media portrayals of the relationship between social class and crime, particularly from a rhetorical perspective. Thus, the applicability of my thesis is apparent. In investigating news coverage of crime, I identify rhetorical messages present within the media, evaluate the ideological beliefs they purport, and explore the potential cultural impacts of those beliefs. To do so, I employ a method that combines McGee's (1980a) notion of the ideograph with a form of framing analysis that seeks to expose pervasive descriptors within articles. The knowledge I glean from this process will help to meet the needs of rhetorical scholarship I have established. 
After examining the relevant body of work that does exist, however, I am able to formulate my preliminary argument: that the rhetoric underlying the coverage of crime within news media serves to uphold a hegemonic ideology that enables the systematic subjugation of the poor in society.

\section{Conclusion}

In this chapter, I have established a scholarly basis for the major issues that concern the thesis I propose. I have reviewed the assertions of academics regarding overarching theoretical concepts such as ideology and social class. I have also isolated gaps within research pertaining to crime and the media to prove the necessity of my project. Lastly, I have drawn connections between all of these ideas to demonstrate their relationship to the study of rhetoric and social power relations. Based on this review of relevant literature, I argue that it is likely that news articles pertaining to crime convey subtle, yet powerful ideological rhetorics that support classist assumptions on the part of its audience.

Within my next chapter, I will further discuss how I investigated news coverage of crime in Detroit - a location I selected due to its cultural significance, as well as because of how the city's social and economic decline is well-documented and has so recently escalated. I will specifically describe how I combined framing analysis with ideographic analysis as a method for rhetorical criticism. I will also elaborate as to how I used Gramscian cultural thought to guide my analysis, as well as how these theoretical considerations affect my critical goals. Finally, I offer a description of the texts I plan to analyze in this thesis, and will greater further justifications for their selection. 


\section{CHAPTER III METHODOLOGY}

In Chapter II, I established a scholarly foundation for my project by discussing literature pertaining to theoretical concepts, including those of ideology, social class, and hegemony. I also reviewed the existing research on the subjects of critical framing analysis, particularly as it relates to representations of social class within newsprint coverage of crime. Finally, I highlighted the relationship between all of these concepts and the notion of rhetoric to fully demonstrate the relevance of my thesis to the communication field. Ultimately, this survey allowed me to establish the foundational argument of this thesis, which is that the classist beliefs of an ideology are able to sustain their dominance in society in part through the rhetorical suggestions present within news coverage of crime.

In this chapter, I will more thoroughly explain the process I used to conduct my analysis. First, I offer a description of the texts I examined and address potential concerns regarding generalizability. Second, I elaborate as to how Gramsci’s (1971) theories regarding cultural hegemony guided my analysis. Third, I describe the methodological processes involved in both ideographic analysis and critical framing analysis, and then explain how I integrated the two methods. Fourth and finally, I specify the procedure with which I explored the texts I have selected. 


\section{Description of the Text}

As I explained in Chapter I, I decided to analyze crime news reporting for the city of Detroit for several reasons. First, given Detroit's size, former economic prosperity, and well-documented decline, I feel that the city is highly significant to U.S. culture. Second, because Detroit's financial instability resulted in its declaration of bankruptcy so recently, I believe that the use of the city as my source of text is particularly timely. Third, news articles regarding the status of Detroit are frequently published in a variety of sources ranging from local newspapers to national news companies, and even to domestic outlets for international news sources.

Detroit Demographic Information. According to the most recent government estimates, Detroit's total population consists of 701,475 people, which has decreased by over 10,000 people over the course of just two years. Further, $10.6 \%$ of the current Detroit population identifies as White, $82.7 \%$ of the population identifies as Black, and $6.8 \%$ of the population identifies as Hispanic or Latino. Among Detroit inhabitants that are 25 years of age or older, $77.2 \%$ possess at least a high school-level diploma, but only $12.3 \%$ of the same group has earned a higher-level degree, as compared to $25.5 \%$ of the same population for Michigan overall (U.S. Census Bureau, 2013). According to CityFacts (2014), the median age of a Detroit resident, is 34.8 years, as compared to a median age of 45.5 years for residents in the state of Michigan as a whole.

The average annual income per capita in the city is $\$ 14,861$ with a median annual household income of $\$ 26,955$, as compared to $\$ 25,547$ per capita and $\$ 48,471$ per household in the state of Michigan as a whole. Further, $38.1 \%$ of the Detroit population is 
considered to be below the poverty level, which is more than double the percentage of the overall Michigan population living below the poverty level (U.S. Census Bureau, 2013). $66.3 \%$ of the Detroit population living in poverty identifies as female. In terms of race, $76.1 \%$ of the city's poor population identifies as Black, and another $12.2 \%$ identifies as a race other than White. Additionally, in terms of the percentage of people living below the poverty line in Detroit per race, $39.3 \%$ of Whites, $40.8 \%$ of Blacks, $40.9 \%$ of Hispanics and Latinos, and $45.5 \%$ for other race residents are poor. As of 2013, the unemployment rate of Detroit was $18.8 \%$, which was more than double the unemployment rate for the state of Michigan as a whole (City-Data, 2014).

According to RealtyTrac (2014), as of February 2014, home sales in Detroit had decreased by $29 \%$ over the course of the past year. Moreover, $25.75 \%$ of the homes in Detroit were abandoned, while $0.09 \%$ of homes are in some stage of the foreclosure process. Finally, Michigan’s Campaign to End Homelessness (2014) organization projected that in 2011, the homeless population of the Detroit Metro area of Michigan consisted of 31,929 people.

Detroit Crime Statistics. Homefacts (2014) generates yearly data reports of crime for each U.S. city based upon the most recent statistics reported by its police reports, and compares the city's crime rate per 100,000 people with the average crime rate of the U.S. as a whole per 100,000 people. Using crime statistics from 2012 on that scale, Detroit averaged 55 murders as compared to 5 in the U.S.; 62 rapes as compared to 27 in the U.S.; 685 robberies as compared to 113 in the U.S.; 1,321 aggravated assaults as compared to 242 in the U.S.; 1,908 burglaries as compared to 670 in the U.S.; 2,258 
larceny thefts as compared to 1,959 in the U.S.; and, 1,626 motor vehicle thefts as compared to 230 in the U.S. In terms of all violent crime, Detroit averaged 2,123 cases as compared to 387 in the U.S., and in terms of all property crime, Detroit averaged 5,792 cases as compared to 2,859 in the U.S. Finally, in terms of the average overall crime rate per 100,000 people, Detroit averaged 1,010 crimes as compared to 301 in the U.S. While it has not yet made crime statistics available for all of 2013, the Detroit Police Department reported that the overall crime rate in the city fell by $6 \%$ since 2012 . Based upon these statistics, however, the city's inhabitants are still at a comparatively high risk of becoming the victim of a crime.

Text Selection. Due to my intention to analyze connections made between crime and poverty in journalism, I focused on articles written during the lowest point in the city's economic decline. Therefore, it seemed appropriate to consider articles written in the temporal context of Detroit's declaration of bankruptcy. As such, using online search engines and news databases such as Google News and Lexis-Nexis, I reviewed news articles published on the Internet that focus upon instances of crime in Detroit, including reports of particular instances of crime, narratives of victims of crime, and those that discuss the culture of crime in Detroit on a larger and more general scale. I opted to focus my analysis on news stories available online because a much larger number of people would have access to those articles, and online news readership is rapidly increasing (Lee, 2013; Saba, 2011). Hence, they could conceivably have a greater social impact than those only published in print form. I only considered articles that were published between July 18, 2013, which was the date that Detroit filed for bankruptcy, and December 31, 
2013. Additionally, both to further aid my selection process and to ensure the relevance of the texts for my purposes in this thesis, I decided only to consider articles that I found upon reading to include descriptions of some type of a relationship between crime and social class. Because news articles are often very concise, I decided that a single article would not be sufficient. I wanted to choose at least ten articles to ensure that I would have a sufficient amount of meaningful text to analyze for a project of this scale. However, given the large scope of my intended methodology, I felt that attempting to analyze any more than fifteen texts would be too large of an undertaking.

I should also note that, while I wanted to choose texts from the most popular news sources so as to ensure their cultural significance, I did not want to limit my analysis only to news from just one or two sources. Therefore, I selected news articles from a variety of different news outlets. Five of my articles were retrieved from news services local to Detroit, including The Detroit News (Hunter, 2013), and The Detroit Free Press (Carlisle, 2013).I also selected news stories written by Buccellato (2013) and Campbell (2013), as well as an article with no by-line, that were each published by a CBS-operated local city media outlet. Another four of the articles I selected were published by nationally-oriented news companies, including Forbes (Fisher, 2013; Muller, 2013), Time (Maynard, 2013), and USA Today (Baldas, 2013). The remaining three articles I chose for my analysis were published by the U.S. news outlets for Al Jazeera (Dudar, 2013; Lewis, 2013) and Reuters (Neavling, 2013).

All of these news sources are met with critical and commercial praise, as suggested by their public popularity, high circulation, and/or online readership. For 
example, both The Detroit News and The Detroit Free Press are immensely popular online news sources, at one point breaking into the ranks of the top five U.S. newspapers in terms of online readership (Edmonds, Guskin, \& Rosenstiel, 2011). The Detroit Free Press and USA Today have both been identified as two of the most popular news sources in the U.S. based on print circulation (Associated Press, 2011, 2012). USA Today is a frontrunner for the newspaper in the nation with the greatest print and online readership (Lee, 2013; USA Today, 2013). Further, USA Today and Forbes have both been found to be among the top fifteen news sources in terms of online readership in the U.S. (Bruner, 2012), as has Al Jazeera (Grandoni, 2012). Time is also well known for its high degree of print circulation, consistently placing in the top 25 of U.S. magazines (Byers, 2012). A recent poll found that CBS news is publically perceived to be trustworthy at comparatively high levels to other sources, as well as very low relative levels of distrust (Jensen, 2014). Further, Reuters is commonly regarded as one of the most important and dominant newswire organizations in the world (Encyclopaedia Britannica, 2014).

Though I did not make a specific effort to select news sources with this characteristic, it is still worth nothing that each of the outlets from which I selected a text is owned by a large corporate company. Al Jazeera, Forbes, and Reuters are each operated by a corporation of the same name, respectively (Al Jazeera America, 2014; Forbes, 2014; Reuters, 2014). The Gannett Company owns and operates both The Detroit Free Press and USA Today (The Detroit Free Press, 2014; USA Today, 2014). The Detroit News is owned by MediaNews Group (The Detroit News, 2014). Finally, CBS 
Detroit is obviously operated by the CBS Corporation, which is owned by the parent company National Amusements, Inc. (CBS Detroit, 2014).

Ultimately then, I selected twelve news articles to analyze in this thesis. I defined "news" simply as articles published within the "news" sections and categories within the respective websites of the aforementioned media outlets. In conducting this examination, I limited my analysis to the core text of each article. This included the entire body of each article, as well as their headlines, subtitles, any quotations from interviews offered within the body, and any headings used within the article organize and label segments of core text. I did not include photographs, graphics, or data sets that were not reported or discussed within the bodies of the articles. I chose not to analyze these elements for three reasons. First, they are only ancillary materials to the content of the articles' core texts, and I preferred to focus my efforts on the stories themselves. Second, the method I employed is ill-suited to analyzing media other than actual text. Third, news databases such as Lexis-Nexis often fail to include pictures, graphs, and the like in their collections of articles. I also refrained from analyzing any captions associated with those discarded elements because, absent a consideration of the images and figures that they were meant to supplement, they were no longer germane to the news stories.

Prior to discussing my theoretical framework, I must address some potential concerns regarding my method of selection. Clearly, I did not use a randomization process. I narrowed my options for potential texts based on the criteria I discussed above: I sought news articles from a variety of sources that cover crime in Detroit, and were also published online between July 18, 2013, and December 31, 2013. After using these 
standards to filter my options, I read through the pool of articles and discarded those that did not offer a discussion of class in addition to the topic of crime. From the remaining articles, I selected the twelve texts that I felt would most powerfully substantiate my argument, as I have no intentions of making claims about generalizability. Several other texts I considered observably upheld hegemonic ideology; those I selected function as examples of problematic crime reports. I do not feel that I am selecting isolated instances to problematize for the sake of my argument; any classist ideology espoused by these articles that I might unveil through my analysis ought to warrant my approach by virtue of the fact that these were published and readily available to consumers of news on a mass scale. I do feel, however, that the nature of my analysis will allow me to consider the implications of these articles in terms of their transferability, or their ability to relate to social phenomena that I do not examine in this study but are contextually similar (Lincoln \& Guba, 1985). Moreover, I will not assert that news media drive people to commit crime. Rather, my argument is more concerned with first, establishing that certain representations of criminals do indeed exist, and second, demonstrating how those representations intersect with hegemonic ideology by potentially serving framing and priming effects.

\section{Theoretical Framework}

As established in Chapter II, Gramsci (1971) problematizes the ability for ideologies to create cultural expectations and disseminating them through the messages of trusted sources. This is problematic because, should the cultural logics undergirded by these messages be internalized the public, they can calcify into social norms about the 
nature of identity and cultural relationships. Once these ideas form a widely accepted network of assumptions, they become what Gramsci describes as common sense - ideas that have woven themselves into social thinking to such a degree that they are rarely challenged. Unfortunately, common sense ideologies frequently perpetuate the social powers of elites at the expense of others in society, resulting in forms of discrimination such as racism, sexism, and as most relevant to this thesis, classism. This process through which an ideology works to systematically oppress some social groups while heralding others through its construction and maintenance of social truths is what Gramsci refers to as hegemony.

I find myself highly influenced by Gramsci's (1971) critique and am therefore concerned with the ability of oppressive ideologies to deploy rhetoric in a way that is so covert and insidious that the marginalized are either unaware that they are being indoctrinated, or else accept social oppression as natural or justified. I find the use of news as rhetorical channel for the espousal of these ideologies to be particularly problematic because so many believe it to be an objective depiction of truth (Gramsci, 2012). As such, I seek to use this thesis as an opportunity to challenge instances of hegemonic social control. According to Hart and Daughton (2004), a mechanism by which these social structures may be interrupted is rhetorical criticism, which is a means of exposing underlying ideological meanings within texts as well as the political goals towards which those ideologies aim.

Given these concerns with oppressive power relations, I plan to perform my analysis through a critical rhetoric approach. McKerrow (1989) defines "critical rhetoric" 
as a view of rhetorical study in which a critic seeks to discern the configurations of power in a society and the nature of messages used to persuade the members of that society to accept those configurations. Zompetti (1997) provides a thorough explanation as to how one should engage in critical rhetorical analysis in such a fashion as to provide the opportunity for social improvement from a Gramscian perspective. He proposes three steps to such work. First, a critic must be self-reflexive; that is, prior to engaging in a critical examination of a text, one must first seek to understand his or her own position in the social world and, more particularly, in the scheme of power relations. Recognition of such a social position is a prerequisite to the opposition of social dominance in any form. Second, discovering one's self in this manner allows the critic to become what Gramsci (1971) refers to as an "organic intellectual," or one who is capable of recognizing the artificiality of social structures and rearticulating the distribution of power in a society. Finally, this ability to rearticulate social relations allows one access to a critical telos, or a point of action and praxis in which the exposure of problematic power structures performed by the rhetorical critic enables the oppressed to recognize their cultures of subordination and unite to resist forms of power, whether that be classism, racism, patriarchy, heteronormativity, or any other form of prejudice. Ultimately, Zompetti indicates that this method of criticism is not only necessary to expose hidden instances of hegemonic dominance, but also to uncover both the methods by which they are sustained as well the ideological sources from which they are generated. This is the role of a genuine rhetorical critic who seeks social change, and as it is my goal to operate in this capacity through my research. 


\section{Data Analysis}

I performed a highly specific form of close textual analysis (CTA) as I

investigate the texts I have chosen. Essentially, CTA is a method by which a rhetorical critic examines a text with a high degree of particularity and focus in order to identify, isolate, and examine specific relevant themes, salient words and phrases, and notable inconsistencies (Sillars \& Gronbeck, 2001). As such, I employ CTA to search for ideographs and frames within my texts.

Ideographic Analysis. McGee (1980a) discusses two perspectives from which a critic may analyze ideographs: diachronic and synchronic. The diachronic, or "vertical" perspective, as McGee explains, is concerned with the examination of an ideograph through time - in other words, a historical examination. The main goal of diachronic analysis is to understand the overall meaning of an ideograph as it is applied to various contexts throughout time.

More relevant to my purposes, however, is synchronic, or "horizontal," analysis. As McGee (1980a) explains, a synchronic consideration of an ideograph is concerned with how the ideograph is deployed in a singular present context. From this point of view, a critic is able to ascertain how an ideograph is used rhetorically in a context to influence an audience or to issue a particularly powerful statement. Moreover, McGee explains that ideographs are designed to function together, meaning that ideographs rely upon each other to create and compound meaning. He provides the examples of the two ideographs < property> and <liberty, > which may be clustered with a third ideograph, $<$ rule of law> (p. 13). <Property> and <liberty> may be distinct ideographs when 
isolated, but their meanings are connected and galvanized when conjoined with < rule of law>. It is in this way that McGee believes ideographs function as building blocks for ideology. Discovering ideographs and arranging them into clusters such as this can reveal the subtle mechanisms by which cultural norms and values come to be through our communication.

Critical Framing Analysis. In their publication calling for scholars to pay greater attention to manifestations of hegemony when performing framing analysis, Carragee and Roefs (2004) suggest that critical framing analysis be conducted by analyzing articles for the presence of potent literary devices, a methodology proposed by Gamson and Lasch (1983). These authors assert that the deployment of salient metaphors, catchphrases, exemplars, visual images, and other particular depictions serve to characterize themes in a way that resonate with the audience, encouraging them to accept these frames as truisms. A rhetorical critic can search media for these literary devices, analyze the covert rhetorical meanings they convey, and explain why the dissemination of those devices allows for the construction and maintenance of oppressive social power relations. Further, Gamson and Lasch indicate that frames successfully persuade audiences to internalize media characterizations due to their inclusion of causal interpretations of issues, consequences of those issues, and appeals to commonly shared moral principles. A critical scholar could break news stories down into these components and analyze how these three elements enable dominant ideologies to persuade the audience as to the nature of the causes of societal problems that run counter to the socially constructed ideas they have come to accept. 
Entman (1993) offers other elements one may consider when performing a rhetorical critique based in framing analysis. First, he extends relevant literary devices to include the depictions of cultural stereotypes, both in terms of actual images as well as textual representation. A rhetorical critic would likely be able to simply pick out stereotypical negative images of marginalized populations in the news media and explain how the essentialization inherent in such representations seems to justify widespread prejudice on the part of the non-marginalized members of society. Further, Entman indicates that because frames are inherently selective of the material they convey to audiences, they thus have to be inherently exclusive as well. A critical framing scholar could speculate as to what kind of material is omitted from a news story in favor of the more dominant portrayals, as well as the implications such omission has upon the public's consideration of the information presented in that article.

Ultimately, in analyzing both ideographs and frames found through CTA, I to investigate potential connections between the two concepts - an examination that is by and large lacking in the field of rhetorical scholarship. I speculate that ideographs and frames are highly interrelated, and that value-laden ideographs function as components of overarching frames in the news, serving to inject themes, narratives, and metaphors with powerful cultural meanings that resonate with audiences and promote ideology.

\section{Procedure for Analysis}

To perform my analysis, I first engaged in CTA as I read through each news article that I have selected as a text. As I examined each news article, I searched for and isolated ideographs as well as frame components. It was not difficult to locate ideographs 
within my texts; as McGee (1980a) jocularly explains, terms so loaded with meaning do not exactly "hide" within discourse. It is certainly true that some words may carry ideological meanings, but do not hold enough power to be considered an ideograph. For example, the word "labor" is certainly relevant to the ideology of capitalism; however, it is not charged with an ideological evaluation, unlike the term <labor union>. Therefore, I was able to dismiss similar words from my ideographic analysis of these news articles by determining whether such a value judgment was implicit within their usage.

Components of frames were more difficult for me to identify. However, I used Entman (1993) and Gamson and Lasch's (1983) conceptions of framing elements, such as the presentation of sensory descriptions in discourse that result in the construction of stereotypical images, consistent descriptors, value-laden metaphors, and salient exemplars, as a guide. The most difficult part of the process was to consider the implications of any omissions made in the articles. I had to be aware of instances in which my articles referred to a person or groups of people, yet did not offer them an opportunity to speak for themselves. This was challenging, but worthwhile - as McKerrow (1989) indicates, omission can serve a powerful rhetorical function. For example, in these cases, omissions could suggest that the people to whom the articles refer were not worthy of the opportunity to provide their own voices.

My next step was to conduct the synchronic analysis of the ideographs I discovered within my texts. In this process, I evaluated each ideograph in terms of the cultural meanings with which it emanates so that I could understand what types of social values it was meant to evoke. Once I was clear as to the nature of these meanings, I 
organized the ideographs into clusters so and began to conceptualize the ways in which they are related, just as McGee (1980a) did with his example of <property>, <liberty>, and $<$ rule of law $>$.

After I arranged the ideographs into these clusters of connection, I turned to framing components I was able to identify within the articles. As I had just done with the ideographs, I coded the descriptors, stereotypes, and other elements I discovered into categories of similarity. Once this was complete, I began to develop overarching rhetorical themes from categories of framing components and any relationships I was able to perceive between them. As I explained in Chapter II, my conception of "rhetoric" for the purposes of this thesis corresponds with McGee's (1980a) definition, which is a politically motivated attempt to persuade an audience. To help me understand the potential political motivations of the ideologies undergirding these themes, I incorporated the Gramscian lens I previously discussed. I considered the ways in which the meanings I have uncovered from within my texts might reinforce or even strengthen a cultural hegemony that allows for the heralding of the wealthy while forcing the poor to the peripheries of society.

Finally, upon having developed my framing themes and my clusters of related ideographs, I cross-referenced the ideographs and frames to explore potential relationships between the two groups. Specifically, I sought to answer such questions as: Do any of the meanings espoused by the clusters of ideographs correspond with descriptions made or narratives offered by the categories of framings elements? Are the ideographs able to provide greater meaning to the categories of frames? Finally, can the 
ideographs be coded within the categories developed for the framing elements? Through this approach, I was able to identify a number of rhetorical mechanisms that could enable a classist ideology to perpetuate itself through the discourse of the texts.

\section{Conclusion}

In this chapter, I have provided a more detailed explanation of the process I employ to analyze the content of news stories pertaining to instances of crime in Detroit. I specifically explained my rationale for selecting crime news coverage regarding Detroit. Finally, I also clarified the theoretical approach I am taking as I pursue my analysis, as well as my goal to unearth and challenge any mechanisms of hegemonic control I may find within my texts.

Chapter IV contains a description of my findings from my analysis of the news articles. Particularly, in the next section of this thesis, I offer a discussion of the relationship between ideographs and framing that is present within my texts. I also identify prevalent themes that exist throughout the articles I selected, provide evidence of those themes, and explain how they relate to Gramsci's (1971) notion of cultural hegemony. 


\title{
CHAPTER IV
}

\begin{abstract}
ANALYSIS
Chapter III explained the methodological process I used to conduct my analysis. Particularly, I first surveyed available data to describe the social conditions of Detroit and explained the criteria I used to select news articles to serve as texts in my analysis. Second, I discussed a theoretical framework with which I approached my critical examination of these texts. I then explained how critical framing analysis and ideographic analysis function as methods in rhetorical criticism. Finally, I specifically outlined the procedure I used to investigate the examples of criminal news coverage I chose.

In this chapter, I present and discuss the constructs of ideological rhetoric I found in each phase of my analysis, and explain how we may use Gramsci's (1971) theories of cultural hegemony to understand how such discourse may function in creating and maintaining the social logics that justify disparate social power formations. Specifically, I first describe my findings from the ideographic analysis I performed. Second, I will explain and provide examples of the narrative themes fashioned by the framing elements I uncovered from the news articles. Lastly, I will explain the relationships between the ideographs and framing themes, and discuss how a dominant ideology's deployment of both may impact the rhetorical nature of the texts.
\end{abstract}




\section{Ideographic Analysis}

As stated in previous chapters, McGee (1980a) identifies ideographs as words that convey meanings to members of a culture that reach far beyond their denotative definitions. These terms evoke images, values, beliefs, memories, and/or understandings of history within the thoughts of those who hear or see them, thereby serving to harken back to some underlying ideology. I performed a synchronic analysis of the ideographs within the news articles I selected, meaning that I isolated terms that seemed to resonate in a certain way, examined the discursive contexts in which the terms were deployed in order to understand the cultural logics they support, and finally, analyzed how these ideographs may compound the meanings of one another in order to further strengthen an ideology.

From my analysis, I was able to identify three independently pervasive ideographs: <crime>, <bankruptcy>, and <homeless>. I also argue that words that are etymologically related to these ideographs, such as <criminal $>,\langle$ bankrupt $\rangle$, and $<$ homelessness>, function ideographically in the same ways as the words with whom they share base terms. In this section, I will explain how these three words are ideographs and, further, discuss how they are used to support an ideology of classism. I will use references to my texts, as well as arguments made in the scholarship surveyed in Chapter II, as evidence to support my claims. After discussing the ideographs independently, I will use McGee's (1980a) clustering technique to demonstrate how they function together to promote that repressive social framework. 
Prior to proceeding, however, I will address the argument that these three terms are not sufficiently salient to be considered ideographs. First, all of the scholarship I review in Chapter II regarding the social connotations of both deviance and economic class suggests that these concepts are critically important to our understandings of society and culture at large; thus, it follows that the terms used to refer to these phenomena ought to be considered ideographs. Second, as McGee (1980a) explains, one rhetorical function of ideographs is the construction of boundaries of cultural identity. Different groups are united by different values and experiences, and as such, terms that function as ideographs for one group may not function in that way for another. Therefore, I argue that even if not all people in the U.S. conceive of these four terms as ideographs, the terms at the very minimum resonate as ideographs among the people that live in Detroit due to the city's social conditions and recent economic events. Third and relatedly, it is important to note that these ideographs are deployed in news media that, as Gramsci $(1979,2012)$ argues, are both perceived as an objective source and are disseminated to a mass audience. As a result, the characterizations of these terms within these texts can transcend Detroit's cultural barrier and construct themselves as ideographs in the minds of a much wider audience.

$<$ Crime $>$. Based upon the conclusions advanced by the other scholars I have discussed, it may already be apparent that <crime> functions on an ideographic level. Just as Wonders (2009) suggests that society constructs positive identities for those who conform to cultural norms, Nielsen et al. (2009) argue that society constructs negative identities for those who do not - often to the point that, Becker (1963) explains, deviants 
are not able to deconstruct the labels they receive. Further, because it denotatively refers to behaviors that are so extremely deviant that they violate legal codes, <crime> is regarded as particularly abhorrent by dominant ideology (White \& Perrone, 2005). If <crime> is so culturally significant as to warrant such grand consideration, it must function ideographically.

To further demonstrate <crime> as an ideograph, I will examine it in the specific context of news coverage concerning Detroit crime. The authors of my texts construct <crime> as an ideograph in several different ways. Most notably, it is used as a label for vivid descriptions of deviant behavior within the news articles, including those that are violent (Carlisle, 2013; CBS News, 2013; Dudar, 2013; Hunter, 2013; Lewis, 2013; Maynard, 2013; Neavling, 2013). Sometimes, these journalists will present a rapid list of such instances and then use <crime> as an ultimate characterization. For example, Lewis, a journalist with Al Jazeera America, writes:

On Sunday, a baby girl was delivered after her mother was shot dead, but later died in the hospital, on the city's west side. Wednesday, a promising law student was found in her car in a vacant lot after she was shot in the head. The same day, three men were killed and six wounded after gunfire erupted in a barbershop known for gambling. Meanwhile the killing of a teenage girl, shot in the head last Saturday on a stranger's porch while asking for help after a car accident, has increased racial tensions in the city.

The list of killing goes on. 
Immediately after surveying examples of violence in this way, Lewis quotes Detroit Police spokesperson Sgt. Michael Woody, who states that "The reality of it is we've had a violent week of crime." As a result of these descriptions, $<$ crime $>$ is no longer conceptualized merely as an act that violates the code of law; rather, the word carries with it examples of images and stories that necessitate its understanding in cultural terms that go beyond its denotative definition.

Several of the texts also discuss <criminals $>$ and instances of $<$ crime $>$ in terms of the emotional responses they incite from ordinary citizens. Al Jazeera America journalist Dudar (2013), for example, writes about Detroit liquor store owner Maher Bacall, who is saddened by the occurrences of <crime> in the city and his inability to prevent them. In other news stories, CBS News (2013), Hunter, (2013), Lewis (2013), and Maynard (2013) describe individuals and groups in Detroit who are angered by the city's conditions; for example, a CBS News (2013) article with no byline mentions that one citizen who observed the police making an arrest shouted, "About damn time!" Finally, and perhaps most notably, Carlisle (2013) of The Detroit Free Press and CBS News (2013) describe <crime> as a concept that instills fear in ordinary members of society. Indeed, Carlisle's (2013) article features the narratives of Detroit residents Renee Gilmore, Lenorris Travier, and Deborah Hunt-Cooper, all of whom have suffered from multiple home break-ins and burglaries. Each of Carlisle's interviewees report feeling traumatized in some capacity, and explain that they can no longer feel safe or at peace. These news reports inculcate references to <crime> with powerfully negative emotions, enabling people who read them to respond to mentions of <crime> in these and other 
sources with similar feelings. The incorporation of these emotions into <crime> allows the term to surpass its denotative definition in an additional way, thus further establishing itself as an ideograph.

Finally, the articles I analyzed establish <crime> as an ideograph in another way by overtly depicting it as a cultural problem with great social significance. For example, Baldas (2013), a journalist for USA Today, reports the results of a poll in which Detroit citizens were asked to indicate what they felt was the biggest problem facing the city. She writes, "Crime topped that list, with 46 percent of respondents listing crime, drugs, gangs and violence as their top concern." Accordingly, CBS News contributor Buccellato (2013) writes that in the 2013 Detroit mayoral election, both candidates' primary platforms emphasized their agendas to combat <crime> in the city. Further, Lewis (2013) reports that community watch groups and other anti-<crime> movements have sprung up throughout the city, all of whom plan to "saturate" their neighborhoods with messages indicting <criminal> behavior. The discourse of articles like these further constructs <crime> as an ideograph by portraying the behavior to which it refers as an issue at the core of social and political consideration, thereby encouraging the public to also conceptualize it as important. According to Gerbner's (1973) cultivation theory, even readers who do not live in Detroit are likely to transfer these connotations of $\langle$ crime $\rangle$ to their own social expectations through a process of acculturation, in which they use representations of the outside world within media to configure their beliefs as to the nature of other people and places. In this way, their consumption of the news allows these 
representations to supplant social beliefs that may have resulted from actual life experiences.

Discourse including <crime> and <criminals> has clear ideological implications. The terms do not function to generically label acts of deviance and those who commit them. Instead, they evoke vivid images in the minds of those who consume them, such as instances of violence or of financial exploitation. Further, these terms do not only force people who hear them to think of examples of such deviance in their social experiences; as suggested by several of the texts, the thought of <crime> promotes powerful negative emotions in audiences (Carlisle, 2013; CBS News, 2013; Dudar, 2013; Lewis, 2013), such as fear, sadness, and anger, in those made to consider it. Ultimately then, <crime> is used to convey threat.

Certainly, this includes threats to the lives and well-being of potential victims of <crime>. Moreover, <crime> also threatens a set of cultural values, such as protecting the lives of innocents who do not stray from socially sanctioned behaviors, or seek genuine employment as an honest means of earning money. In this way, <crime> as an ideograph promotes society's adherence to the normalized acts and beliefs of an ideology through its contrasting treatment of deviant behaviors, as well as those who commit them, as dangerous and malicious. Such logic renders a hegemony's cultural exclusion of a person or group of people to the margins of society as justifiable, so long as this exclusion is predicated upon their noncompliance (Gramsci, 1971). Though this ideograph does not in and of itself promote classism, it does promote the homogenization of behavior. 
Therefore, its connection to ideographs that portray the poor negatively would support classist beliefs, as I will explore later in this analysis.

$<$ Bankruptcy $>$. $<$ Bankruptcy $>$ is also an ideograph due to the negative cultural response it invokes. Brantley et al. (2003) state that a pervasive, if sometimes underlying, belief in the U.S. is that the wealthy are socially superior to those who are less wealthy, even to the point that the poor inhibit the progress and well-being of the non-poor. For example, popular political commentator Glenn Beck (2010) makes this argument in his comparison of the social impact of one's choice between renting a home and owning a home, a discussion in which he concludes that poor people need to rent. Beck claims that as a culture, we should discourage the poor from owning homes because they do not deserve the privilege of ownership, and further, the poor will become burdens to society when they inevitably foreclose on their properties.

Similarly, Michalowski (2009) asserts that those in poverty are deemed to be not only weaker than those who are financially secure, but are also culpable for any suffering that results from their poverty. He argues that the poor receive this blame because social class is perceived to be a controllable characteristic, determined entirely by one's willingness to work hard. As Entman and Rojecki (2000) explain, this belief inspires a fear of poverty in society. It follows, then, that a financial status explicitly marking a person or institution as poor, such as <bankrupt $\rangle$, would be regarded with a similar connotation. Indeed, the cultural distaste surrounding the idea of <bankruptcy $>$ is particularly severe because it is deeply entwined with the law, and therefore suggests that afflicted persons or institutions are so financially incompetent that the state was forced to 
intervene and codify them as such. Because of this relationship between labels and laws, <bankruptcy> functions in a similar rhetorical capacity to <crime>. Moreover, it likely espouses further cultural meaning because, as a result of the recent and widespread economic ills in the U.S., <bankruptcy> has become increasingly common - applying not only to individuals and businesses, but also to cities, as evidenced by Detroit.

In the texts I selected, the cultural salience of <bankruptcy $>$ is enhanced in a variety of ways. First, Maynard (2013), a staff writer for Time, expresses that the conditions of Detroit's declaration of $<$ bankruptcy $>$ plummeted the city, which she argues could theoretically be a place of economic opportunity, to a dangerous position. She writes:

The juxtaposition of the city's potential and its difficult present illustrates the fragility of Detroit's comeback — and shows how difficult the task will be for the elected officials, business leaders and others who hope to rebuild the city, which filed for Chapter 9 bankruptcy this summer.

The language here serves to warn readers that <bankruptcy> is a status from which an entity could possibly be unable to recover. Further, Detroit's recent declaration of <bankruptcy> layers the term with additional meaning, as this event marked the first instance in which such a large and culturally significant municipality filed for the status. Dudar (2013) and Fisher (2013), a staff writer for Forbes, report that Detroit is the largest American city to ever file for <bankruptcy>, while Baldas (2013) describes the situation as "historic." Such discourse magnifies the already negative connotation of <bankruptcy> 
by forcing its audience to consider this financial status as devastating, as well as applicable to the much further-reaching context of a city.

Reporters also ascribe emotions to <bankruptcy> in news coverage, reinforcing the term as an ideograph by enabling it to evoke these thoughts and feelings from their readers. For example, Fisher (2013) describes Detroit's $<$ bankruptcy $>$ as a "crushing financial woe," and further indicates that the Detroit population is "demoralized." The sentiments are echoed by a Baldas' (2013) article, which features data from a poll of Detroit citizens. She explains that according to the results of the poll, the majority of the city does not approve of the declaration of <bankruptcy>, and further, a vast plurality stated that "they believed the city of Detroit is headed in the wrong direction." Clearly, saturating the term <bankruptcy> with these sorrowful emotions further configures the meanings imparted by the term to supersede its basic definition by additionally evaluating it as undesirable.

Lastly, <bankruptcy> is commonly discussed by these texts in terms of its effects on Detroit. These consequences are almost always depicted to be extremely adverse, such as an "underfunded police force" (Fisher, 2013). Moreover, Forbes staff writer Muller (2013) explains that <bankruptcy> has resulted in debt and blight, while Reuters journalist Neavling (2013) makes a reference to "strained city services." Further, on several occasions, these reporters refer to <bankruptcy> and then offer a litany of examples of the various penalties that may be attributed to the declaration of such as status. This is similar to the way that Lewis (2013) characterizes <crime>, as previously explained. For example, Lewis writes: 
Detroit filed for Chapter 9 bankruptcy in July, with a debt of about \$18bn. The filing is the largest municipal bankruptcy filing in U.S. history, and the economic impact can be seen throughout the city in its abandoned buildings, vacant lots, and unemployment rates of over 18 percent.

In this way, the denotative meaning of < bankruptcy> is compounded; not only is it characterized as resoundingly negative in yet another way, but readers are also encouraged to also ponder these various examples of the social impacts of <bankruptcy> whenever the term is deployed.

Although it may seem obvious that <bankruptcy> be met with such a negative connotation, these meanings with which it resounds carry ideological suggestions that are highly important to note. <Bankruptcy > is a devastating label of poverty, and those who are met with it are demoralized and forced to cope with debilitating social conditions; accordingly, people who encounter this term in discourse will likely respond with the fear associated with poverty which, as explained by Entman and Rojecki (2000), is culture's most significant symbol of failure. Furthermore, just as <crime> is the ultimate act of social deviance because of its relationship to norms codified into law, the acquisition of a $<$ bankrupt $>$ status similarly reflects an extreme position of poverty and economic instability. Moreover, it is notable that <bankruptcy> is a financial status which an entity must itself request, further promoting the belief that the poor are responsible for their own conditions. As a result, an ideology persists that rewards the "hard work" of the wealthy with what Bourdieu (1999) refers to as social capital, which constitutes prestige and cultural influence, while forcing the poor to the peripheries of society (Gramsci, 
1971). These social logics justify the social power disparities described by Brantley et al. (2003).

$<$ Homeless $>$. The term <homeless $>$ functions as an ideograph in a very similar way to <bankruptcy $>$. As previously explained, a dominant ideology in this culture promotes the belief that one's social class is self-determined, and that his or her ability to economically advance in society is dependent upon his or her willingness to work (Michalowski, 2009). Indeed, this idea of the "American Dream" is so deeply engrained in us that we have become afraid of the possibility that we fall to the bottom of the socioeconomic ladder (Entman \& Rojecki, 2000). It is for this reason that the term <homeless> is an ideograph. Occupying such a position, as Michalowski (2009) argues, enables us to be demonized by the financially secure members of society as lazy and unwilling to do the work necessary to thrive.

The texts I analyzed further construct <homeless> as an ideograph in a variety of ways. First, <homeless> individuals are frequently associated with other forms of deviance. For example, Hunter's (2013) article within The Detroit News equates the $<$ homeless > population of southwest Detroit with others who violate social norms, such as prostitutes, strippers, drug addicts, robbers, and carjackers. Further, Campbell's (2013) article for CBS News detailing the Detroit Police Department's effort to remove the $<$ homeless > and the debris they create from highway underpasses includes quotations from Lt. Ken Libanski, an officer involved in the project. Libanski states that some of the objects left behind by the $<$ homeless $>$ are "dangerous," and also describes a gathering place for the $<$ homeless $>$ in an underpass as a "heroin shooting range." Campbell also 
cites Jerome Chandler, a member of a <homeless> aid group called Project Helping Hands that is assisting the police in attempting to relocate those who take shelter in the underpasses. Chandler explains that often, the $<$ homeless $>$ have "substance abuse problems" and/or "mental health problems." Associations between the $<$ homeless $>$ and other deviant identities such as those presented in this article further construct $<$ homeless> populations themselves as deviant, or even dangerous. This justifies their demonization on the part of non-poor members of society.

A classist ideology is also promoted by the ideograph <homeless> when those to whom the term refers are represented as societal dregs that pester, victimize, and even rely upon the sacrifices of wealthier members of the culture. Campbell's (2013) discussion of the underpass cleanup efforts posits the <homeless> as individuals whose actions and belongings pose danger to the rest of Detroit, and further, illustrates them as "needing" help from social structures like the police or from self-sacrificing citizens such as Chandler. Additionally, Hunter's (2013) article includes a quotation from Detroit resident Thomas Whitehead, who similarly denigrates the <homeless>. In a description of his neighborhood in southwest Detroit, he states, "It's pretty bad out here. There are a lot of homeless people and drug addicts who hassle you.” These portrayals further establish the ideographic function of $<$ homeless $>$ by providing readers with essentializing images of the $<$ homeless' $>$ behaving in ways that threaten the status of those in higher classes, and moreover, evaluating such behaviors as problematic.

Lastly, the ideographic nature of the <homeless> is also established in the texts by characterizations of the <homeless> as people who are capable of improving their 
economic positions, yet, by and large, are opting to live self-defeating lifestyles. This is best illustrated by Campbell (2013), who writes:

Chandler, who's been working with the homeless for six years, said he's seen plenty of people turn their lives around.

"There's a lot of success stories," Chandler said. "About a year later, you'll see them and you don't recognize them. I recognized one guy — he was using an ATM machine. He had a job and a car ... so, you can move on.”

Even though <homeless> people are able to improve their lives and progress economically, however, Campbell also suggests that there are many who refuse to improve their living conditions. He states, "Police say the homeless residing in these areas will be moved to shelters - if they agree to go. Those who refuse to go to shelters will still be forced to vacate the underpass area." Even when offered assistance in seizing opportunities to better their lives, there are <homeless> who reject it. Incorporating the ideograph $<$ homeless $>$ in these narratives concretizes the classist ideological beliefs that everyone can succeed in society if they exert sufficient effort, and therefore, those who do not succeed must not work hard enough.

In the end, these texts associate the <homeless> population with deviance, the victimization of the non-poor, and an unwillingness to do what is necessary to financially prosper. As such, the <homeless> function as an ideograph because they symbolize the very opposite of the qualities idealized by the American Dream, and illustrate those inverted qualities in a way that is resoundingly negative. Not only does the construction of this ideograph represent both the poor and non-poor as deserving of the respective 
social implications attributed to their wealth, but it also characterizes the lower class as an amoral threat to the well-being of upper classes. By deploying references to the <homeless> in this way, these news articles propagate an ideology that encourages the construction of distinctions between the economically successful and the economically debilitated, thereby justifying the social prestige of the wealthy as well as the subjugation of the poor. This social configuration mirrors the processes of hegemony as described by Gramsci (1971), in which common sense assumptions about the nature of social identity treat the marginalization of the subaltern as inevitable and/or justifiable. If social inequality is considered to be so natural, then the indoctrinated public will not question it.

Cluster Analysis. By independently analyzing the synchronic uses of <crime>, $<$ bankruptcy>, and <homeless >, I was able to establish that the terms function as ideographs by indicating that existence of each is somehow based upon ideological constructions of different social identities and the relationships between those identities. I also demonstrated that they function as ideographs by examining the way the news articles use the ideographic terms in ways that require readers to conceive of the terms with additional thoughts, emotions, and judgments that far exceed their basic denotative meanings. The independent analysis above also suggests that each ideograph is impregnated with an ideology that justifies the maintenance of cultural systems that enable some to possess power while forcing others into socially oppressive conditions. More specifically, <crime> stigmatizes those who do not conform to codified expectations of social behavior, whereas < bankruptcy> and <homeless> enable the subjugation of those who fail to achieve financial success. Now, I will engage in 
McGee's (1980a) cluster analysis, in which I will examine the rhetorical effects created by first, reading across the articles to consider the relationships between the ideographs, and second, discussing how these compounded meanings construct a dominant and oppressive ideology.

In the discourse of these articles, it seems that $<$ bankruptcy $>$ and $<$ crime $>$ have a relationship: the social consequences of Detroit's $<$ bankruptcy $>$ correspond with $<$ criminal $>$ activity. Several of the journalists explain that Detroit's status as $<$ bankrupt $>$ forced the city to cut service resources, including those allocated to the police force, resulting in a law enforcement branch that cannot effectively respond to crime (Dudar, 2013; Fisher, 2013; Maynard, 2013; Neavling, 2013). For example, after discussing other major American cities with "full-fledged police departments," Fisher writes: That barely applies to Detroit, which has been forced to cut back so much that some quip they can have a pizza delivered in less time than it takes to get a police car. There are reasons for hope, however. City government, long dismissed as hopelessly inefficient and corrupt, has been put in the hands of a state-appointed emergency manager, Kevyn Orr. One of Orr's most significant moves was to recruit former Cincinnati police chief James Craig, a Detroit native, to run the city's demoralized and underfunded police force in July.

Similarly, Baldas (2013), Buccellato (2013), and Lewis (2013) all indicate that a $<$ bankrupt $>$ Detroit's reduction of funds for other services, such as aid for the unemployed and youth programs, is also a factor that is encouraging <crime>. In the end, the texts do effectively demonstrate a correlation between <bankruptcy> and <crime> by 
tying <crime> to overarching social conditions. However, there is no explicit discussion of a deeper relationship between the two concepts.

The texts I selected construct a similar correlative relationship between the <homeless> and <crime>. More specifically, the representations of the <homeless> population within the articles are all closely associated with <criminal behavior>. Campbell (2013) depicts <homeless> people as vagrants who could opt to improve their economic conditions and, correspondingly, their lives, but instead choose to consume illegal drugs and defile the city with debris. Hunter (2013) illustrates the <homeless> in a likewise manner, suggesting that they harass ordinary citizens and lumping them in the same category as <criminals>, such as prostitutes and thieves. These characterizations ultimately function to merge the two ideographs: the <homeless> are <criminals>.

On a superficial level, these news articles do not establish a connection between <bankruptcy> and the <homeless >. This may seem bizarre, as the two ideas clearly have a relationship. In the texts, both terms are correlatively linked to <crime>. Further, it is obvious that they both are closely tied to the notion of economics on both a denotative level, as well as an ideographic level on which they tout the superiority of the wealthy to the poor. In considering all of this, it is necessary to refer to Entman and Rojecki (2000). Again, these authors suggest that the news rarely offers an explicit discussion of poverty; rather, the media refer to it implicitly by disseminating coverage of the symptoms of poverty. Certainly, <bankruptcy> and <homelessness > are examples of the symptoms caused by poverty. Further, from an ideological perspective, if <bankruptcy $>$ and $<$ homelessness $>$ function ideographically as effects of one's failure to socially progress, 
then poverty must function ideographically as their cause. Therefore, I can establish that hidden within the discourse of the texts I selected is <poverty>: a fourth ideograph that can only be discerned by clustering the other three and examining their relationships. Underlying both <bankruptcy> and <homelessness> is this symptomatic connection. Therefore, throughout the rest of this thesis, I will use carrotting to note < poverty> as an ideograph. I will not, however, do the same with the word "poor," as it is used to define one's financial status and not to refer to an overarching social condition.

While < poverty> is not a clustered term, it is clearly a culturally-charged word, the meanings of which lurk beneath the more overt language in the articles. Notably, my findings here certainly corroborate those of Entman and Rojecki (2000); though <poverty> is a concept of great import to these articles, the actual term itself is only deployed twice across the twelve articles, and in both instances the term is only used to refer tangentially to the population of the poor in Detroit rather than to social conditions (Buccellato, 2013; Dudar, 2013). As Derrida (1972/1991) explains, concepts and arguments can be very much present in texts, even when they appear to be absent on the surface. He writes:

The absence... is determined in the most classical fashion as a continuous modification, a progressive extenuation of presence. Representation regularly supplements presence. But this operation of supplementation is not exhibited as a break in presence, but rather as a reparation and a continuous, homogenous modification of presence in representation (p. 88). 
Indeed, the absence of an explicit argument in a text to which it is clearly relevant actually serves to endorse that argument, implying its truth within the text rather than exposing it and enabling it to be questioned.

\section{Critical Framing Analysis}

Now that I have concluded my ideographic analysis using McGee's (1980a) notion of clustering, I will begin my discussion of framing. As Nelson et al. (1997) explain, frames are subtle yet pervasive characterizations deployed in news stories that lead media consumers to consider the issues covered in particular ways. Framing analysis is distinct from ideographic analysis because while ideographic analysis is concerned with the rhetorical impacts of specific terms, framing analysis seeks to uncover the overall manner in which the news construct issues into stories. While the consideration of language is certainly still very important to this end, less focus is placed upon the particular words than on the discursive construction of overall contexts. Several critical scholars connect framing theory to ideology (Carragee \& Roefs, 2004; Holstein, 2003; Tuchman, 1978). They assert that these frames operate on a rhetorical level, and may be used to justify concentrations of power in the hands of a few members of society at the expense of others. I argue that, just as a dominant, classist ideology deployed ideographs in the news media to justify the subjugation of the poor, it also deployed particular frames that further propagate this cultural logic by narrativizing people in <poverty> as $<$ criminals .

To demonstrate this, I analyzed the selected texts pertaining to news coverage of $<$ crime $>$ in Detroit by searching for framing elements, including Gamson and Lasch's 
(1983) salient metaphors and frequent descriptors and Entman's (1993) verbal stereotypes and potential omissions. From the elements I uncovered, I developed six themes through which the news articles may frame the relationship between <crime> and economic status in such a way as to support an ideology marked by classism. These themes include: the use of verbal stereotypes to implicitly refer to poverty, the depiction of the poor as social antagonists, the depiction of the non-poor as victims of the poor, the depiction of the non-poor as social saviors, the depiction of explicit violence, and the depiction of the law as benevolent. As I discuss each theme, I will first, describe the theme more thoroughly; second, provide examples of the theme from the texts I analyzed; and third, explain the implications of the theme as it pertains to ideological rhetoric.

Implicit References to <Poverty>. First, I will describe a theme in which the news articles describe instances and images that are stereotypically characteristic of <poverty> to convey to their audience that the news issue at hand pertains to those social conditions, rather than referring to < poverty> directly. My argument relates to Entman's (1993) assertion that verbal stereotypes can function as framing elements, and also draws upon Entman and Rojecki's (2000) findings that, rather than explicitly discussing <poverty>, journalists subtly hint at its relationship to a news issue by mentioning social phenomena that are stereotypically symptomatic of <poverty>. Although I mentioned this in the previous section of my analysis, it is again pertinent to note here that within all twelve of the texts I analyzed, there were only two occasions in which the word <poverty> is used (Buccellato, 2013; Dudar, 2013). Further, the term was never used to 
refer to social conditions marked by extreme material disadvantage, but rather, to generically indicate the poor population of Detroit.

There are, however, several consistent verbal stereotypes used by the articles to tangentially refer to <poverty>. Perhaps the most notable among them is the description of particular neighborhoods using language such as "tough" and "dangerous" (CBS News, 2013). Buccellato (2013) describes an area in Detroit as "a hot zone for youth violence." Lewis (2013) refers to the city overall as "among the most violent and deadly large cities in the U.S.," while Dudar's (2013) article cites Bacall, who describes Detroit as "a war zone." Some may argue that this language is more specifically meant to indicate that the areas are frequently the scenes of $\langle$ crime $\rangle$, a sentiment with which I agree; however, I will elaborate more fully upon the use of an ideograph as an indication of <poverty> in the cross-referential section of my analysis.

Another commonly used verbal stereotype of <poverty> present within these texts is the description of poor neighborhoods in various states of collapse. Indeed, several of the articles describe areas as including abandoned houses, buildings, or lots to suggest that they are stricken by <poverty> (Baldas, 2013; Dudar, 2013; Muller, 2013). On other occasions, articles characterize neighborhood structures as in some state of disrepair. For example, Dudar, who interviews Detroit resident and business owner Frank Dabaja about his perspective on the conditions of the city, writes:

The census tract that includes Dabaja's business is nearly 20 percent vacant. The number of empty properties might be higher than that, says state demographer 
Ken Darga, because the census does not record condemned lots and non-habitable houses in vacancy data.

As Dabaja walks down the block where his gas station sits, he points out the abandoned homes, broken windows and rubble from house fires.

He stops at a boarded-up redbrick home with pink roses out front and trees growing around it.

"What kind of city would allow people to live like this?" he asks.

Further, Muller (2013) extensively discusses blight in Detroit, while Carlisle (2013) refers to an area in which there are "housing projects." Finally, Dudar (2013), Fisher (2013), and Muller (2013) all explain that neighborhoods in Detroit are suffering from extreme population loss.

I also found that when the articles meant to indicate that Detroit or a neighborhood within the city was marked by <poverty> overall, they would explain that the area was suffering from one particular economic dilemma. Lewis (2013) offers an example of this in her article, when she describes a neighborhood as experiencing a high unemployment rate - an implicit reference to <poverty> also utilized by Buccellato (2013). Further, Buccellato's article features an interview with youth community activist Yusef Shakur, stating:

The forecast for youth violence is bleak according to Shakur. With failing social institutions and few economic opportunities, some Detroit neighborhoods resemble "Third World conditions." Shakur refers to such neighborhoods as "Zombieland." And politically there is no urban agenda at the national level. 
Even though the article is clearly referring to <poverty> in this quotation, it still refers to it through other, more vague language. Similarly, Entman and Rojecki (2000) suggest that another way the news will refer to <poverty> without actually using the term is to identify by name the areas of cities that are pervasively known in society to be poor. In Detroit, articles that mention the eastern (Buccellato, 2013; Carlisle, 22013; CBS News, 2013; Dudar, 2013) and southwestern portions of the city (Buccellato, 2013; Dudar, 2013; Hunter, 2013) refer to <poverty> in this way.

Despite how the term <poverty> is virtually absent from these articles, readers are bombarded with reminders of these social conditions, contrary to the findings of Potter and Kappeler (2012), who say <poverty> is not established as relevant. However, it is truly problematic that there are no notable, explicit discussions of <poverty> or the social factors that result from it. Further, Entman and Rojecki (2000) problematize the use of such stereotypical imagery to describe conditions of <poverty>, arguing that they homogenize the identities of the poor, and also highlight the false construction of difference between the poor and non-poor. Ultimately, absent such delineation of $<$ poverty > in the news in favor of coverage of its various symptoms, consumers are left with the culturally traditional perspective that people fall into <poverty> due to their own lack of work ethic - a logic that enables an ideology justifying the existence of social power disparities that correspond with disparities in wealth. As such, the failure to discuss the cause of <poverty> allows the public to conceive of structural and cultural barriers as justifiable, and therefore, their existence falls into the unquestioned assumptions of Gramsci's (1971) notion of common sense. It follows, then, that 
hegemony is able to perpetuate itself because it is, in fact, these very barriers to social advancement that enable the systemic persistence of <poverty> in the first place.

The Poor as Antagonists. The second framing theme I will discuss pertains to the texts' frequent illustrations of the poor as the antagonists of the narratives they provide about <crime>. The poor are treated as villains who resort to deviant means to achieve their goals, exploiting moral society and affronting its values in the process. Given that each of these articles is indeed about <crime>, the antagonists in the narratives are <criminals>. While this is certainly true, I will continue to refer to them as "antagonists" in this section; there are extended ideological implications to the use of the ideograph <criminal> to label the poor in these news stories that I will discuss more thoroughly in the next section of this chapter.

Several of the texts I selected to analyze are rife with examples of this theme. Carlisle's (2013) article, which presents many narratives of homeowners who have been victimized by burglaries, states:

Deborah Hunt-Cooper has seen them watching her, too. On her block, they're the guys from the housing projects across the street who gather by the sidewalk midafternoon.

"When I first moved here and seen them doing it, I said, 'This is the most ridiculous thing I've ever seen,"” said Hunt-Cooper, 61. "These boys be home all day, and around 5 or 6, they would get dressed up - I'm talking clean shorts, gym shoes, their hair combed — and sit out there and shoot craps. Every day." It also gave them a vantage point to see how long people are gone at work. 
In her eight years here, her home has been broken into seven times.

Although Carlisle does not explicitly refer to these likely offenders as poor, his language contains further examples of the previous theme: the use of verbal stereotypes to implicitly refer to <poverty>. For example, he does indicate that they live in housing projects; further, the fact that they were always home, gambling, and always capable of monitoring neighbors' work habits implies that they were unemployed and thus, likely to be poor.

Buccellato (2013), in his article about youth gang violence, offers a similar, but much more overt, characterization of the antagonists. He writes:

According to the Social Science Research Council, Detroit "has the highest youth unemployment rate (30 percent) and adult unemployment rate (17 percent) of any of the twenty-five largest metro areas." Furthermore, "The data show that education is far less an obstacle in Detroit than diminished opportunities to enter the workforce."

Again, offenders are characterized as likely to be poor. This time, however, the author uses data rather than anecdotal evidence. Later in his article, as mentioned in my discussion of the <poverty> theme, Buccellato refers to an interview with Shakur, who characterizes those likely to become offenders as living in neighborhoods with "third world conditions." While these passages do seem to absolve the antagonists from a small degree of their guilt in committing <crime>, they still frame <criminals> as predominantly poor, and as such, enable the rest of society to assume those who live in <poverty> are dangerous or, at least, deviant. 
This common portrayal of the offenders as poor is an example of what Gamson and Lasch (1983) refer to as a frequent descriptor. As such, these discursive constructions function rhetorically as framing devices that persuade consumers of news media to approach their evaluation of <crime> using these narratives as a mental framework, much like the acculturation process described by Gerbner (1973). Such standardization enables the maintenance of the notion that class identity and engagement in criminal behavior are intrinsically related - an ideological assumption that makes it very easy for the public to justify the construction or maintenance of stereotypes that consign the materially disadvantaged to a subaltern status.

Discourse pertaining to the relationship between <homelessness> and <crime> operates in an ideologically similar way. In my analysis of ideographs, I explained that Campbell (2013) and Hunter (2013) both describe members of Detroit's < homeless $>$ population in ways that conflate their identities with those of more obvious <criminals>, like muggers, carjackers, and drug dealers. The rhetorical placement of <homelessness> within the same category of more malicious and/or dangerous <crimes> generates the notion that the presence of the poor and homeless is comparatively worse than the presence of those who would harm others. This belief is made evermore salient when it is both reported in an "objective" news source (Gramsci, 1971, 2012), and also explicitly advanced in the genuine discourse of an "ordinary" citizen like Whitehead, who compared his interactions with the <homeless> to those with drug dealers. Rhetoric like this immediately creates an association between the poor <homeless> and <criminals> who are comparatively more willing to do harm. Iyengar and Kinder (1987) assert that 
when news outlets offer these moral judgments, consumers of their coverage are primed to evaluate the issue similarly. This suggests that descriptions of those who live in <poverty>, such as those offered by Campbell (2013) and Hunter (2013), allow for the perpetuation of classist attitudes and the ideological stigmatization of those who are part of lower classes. Therefore, society is often not conscious of categorizing the poor as the subaltern (Gramsci, 1971). Further when society is conscious of this characterization, the process seems justifiable, and even perhaps necessary.

The Non-Poor as Victims. I also uncovered a theme in which the <criminal> antics in Detroit, which, as previously established, were portrayed to have been committed by the poor, had significant negative effects on society - largely upon the city's non-poor population (here, "non-poor" refers to members of the working class or higher social positions). Indeed, as Entman and Rojecki (2000) as well as Potter and Kappeler (2012) argue, the middle and sometimes upper classes of society are the people who are primarily victimized by <crime>. Positioning the non-poor as victims directly positions them against the poor who, as I just established, are portrayed as perpetrators, thereby strengthening the hegemony's capability of creating ranked categories of social identity (Gramsci, 1971).

I have already offered a few examples of this pervasive descriptor in the previous section, such as Hunt-Cooper's narrative as described by Carlisle (2013), in which unemployed hoodlums scoped out her working class neighborhood. These stories characterize the non-poor as psychologically wounded by <crime>. Carlisle explains that after she was a victim of a burglary, Hunt-Cooper's "ability to relax and feel safe in her 
own home was gone." Carlisle offers a few other examples of this phenomenon as well. First, he offers the story of Renee Gilmore:

First, she had to put iron bars on her windows. Then, she had two types of alarm systems installed. But despite all the precautions, Renee Gilmore was still scared to enter her east-side Detroit house when she came back from work every evening.

"I could hardly come home without looking at the house first, just to make sure," said Gilmore, 41.

They'd broken in three times so far, tried four other times. Now she had to make sure they weren't still inside.

Her neighborhood, known as Jefferson-Chalmers for the intersection that fronts it, is one of the city's better areas. It has well-maintained historic homes, several active community groups and a strong sense of neighborhood identity. But living in a still-solid neighborhood doesn't give its residents immunity to the burglaries that plague city residents.

Carlisle presents Gilmore as a normal, working woman living in a positive, healthy area inhabited by similar people. However, the conditions in the rest of the city are so poor that <crime> has spread to her innocent neighborhood, infecting her life with fear. A similar narrativization is present in Carlisle's story of hard-working Lenorris Travier and his family:

"You feel real violated," Travier said. "They go through your personal things.".... 
Travier's home was invaded only once, and he wasn't there. But his dad wasn't so lucky. He used to relax on his front porch on Lakewood, just blocks from Travier's house, until the neighborhood thugs saw an elderly man as an easy target.

"He was sitting on the porch, and a young boy came running up on the porch, beat him and took his money," Travier said.

So Travier's brother moved in to help protect their dad. It didn't work. They targeted him, too.

"Some other young folks came running up in there, tied my brother to the bed," Travier said. "They stole his TV and stuff, and stole his car. Only reason he got his car back is when they saw the police, they panicked and crashed into a fire hydrant."

The brother moved out. The father moved to Las Vegas to live with family. And Travier moved away, too.

That's three more people gone from a neighborhood struggling, like the city as a whole, to keep its residents (2013).

Travier's narrative asserts that the trauma suffered by the victimized middle class is so severe that some of them feel forced to flee Detroit. The city, in turn, suffers without their social contributions.

Similar narratives are offered by Dudar (2013), who explains that many small business owners in Detroit operate their establishments while feeling constantly apprehensive about their surroundings, or else attempt to sell their businesses so that they 
may move elsewhere. Notably, these reports indicate that <crime> itself places downward pressure upon economic conditions of an area, increasing the conditions of <poverty> that are suggested to have spurred <crime> in the first place. The representation of this process as cyclical classifies lower class <criminals> as selfdefeating, while members of upper and middle classes are forced to suffer as a result. Another type of narrative that depicts victimization explains how an instance of <crime> resulted in the death of a person or persons characterized as belonging to a wealthier class. An example of this may be seen in the incident described in Lewis's (2013) article discussed in my above establishment of <crime> as an ideograph, in which she lists a series of homicide victims, including a mother and her newborn baby. A similar discussion is presented in Neavling's (2013) article. Perhaps the best examples of these narratives due to their detail, however, are present in Maynard's (2013) report on Detroit murders. For example, she writes:

"The violence is out of control," said Bishop Charles Ellis of Greater Grace Temple, who leads a 6,000-member congregation on Detroit's northwest side. "We have to find a way to harness it, police it, all hands on deck. It is going to take all of us in the end to bring some sanity back."

The violence hit home for Ellis on Nov. 4, when his brother-in-law Dwayne Green was found shot to death at his home. Green, 48, was the maintenance supervisor at Greater Grace, where he had worked for 15 years. Ellis's narrative does not only include the story of the murder of a blue collar man, but also illustrates its effect on another member of non-poor society. The deployment of this 
characterization allows the story to seem more genuine and impactful, increasing its resonance with news readers. Maynard also tells the story of Tiane Brown's murder, writing:

Midtown experienced its own brush with violence last month, when third-year Wayne State University law student Tiane Brown was killed. Her body was found Oct. 30, near the abandoned Packard Motors manufacturing complex, which looms as a symbol of the blight Detroit is trying to erase.

Brown, a 33-year-old mother of three, already had earned two degrees (one in biomedical engineering), started a nonprofit and was one of just six students in the inaugural class of the university's patent-law clinic.

Detroit is the only city in the nation with a branch of the U.S. Patent Office, owing to its proximity to the car companies, their suppliers and the state's major universities. Students in the patent-law clinic must be engineers and spend 130 hours per semester researching applications and advising applicants, said Professor Eric C. Williams, who oversees the project. "People like that stand out, they're rare," he said of Brown. "The city is the poorer for losing her."

This description of Brown's death is a clear exemplar of the victimization theme. She is represented as an intelligent, hard-working mother who, through her establishment of a nonprofit organization, strove to improve the conditions of the city. Despite this, Brown was still murdered in a senseless <criminal> act. Interestingly, Maynard concludes Brown's narrative with the quotation from Williams, who uses the term "poorer" to describe the state of Detroit after her murder. Here, the social impact of the victimization 
of a non-poor person is expressed in material terms. This suggests that, first, we may use economic evaluations to understand the role of a human life in the grander scheme of society. Second, the implication of Williams's remark is that the quality of Detroit has lessened as a result of Brown's demise, essentially equivocating the construction of the lower class with low moral quality.

Narratives like these that depict the psychological and/or physical suffering of the middle class resonate with audiences. Media like this offer a value judgment of the issue as described by Iyengar and Kinder (1987), and therefore, they effectively prime their audiences to feel the same emotions and make similar moral evaluations. In this case, these narratives induce in readers the emotions of pity for the affected families, and, in turn, elicit disgust for those who subjected the family to the trauma - who, as explained in the previous theme, tend to be representatives of the lower class. Such emotion-laden accounts are powerful rhetorical mechanisms because they stimulate strong responses from their audiences. In these cases, the stories construct the poor as villains and the nonpoor as martyrs and innocents, which is a highly rigid and artificial dichotomy that, nevertheless, reifies the classes' relative moral and cultural positions in society.

Also present within some of these texts is the narrative of an ordinary citizen who, while perhaps not subjected to violence or psychological torment by lower class antagonists, are still victimized by virtue of inconvenience. Generally, this version of the victimization theme pertains to the representations of relationships between the non-poor and the <homeless> population of Detroit. An example of this is provided above in my discussion of <homelessness> as an ideograph; Hunter (2013) depicts Whitehead as an 
ordinary man pestered by <homeless> persons, who, again, receive the same categorization as violent criminals. Further, Campbell's article pertaining to the cleanup of highway underpasses states:

An effort underway to clean up junk that's cluttering Detroit-area freeway underpasses includes relocating some of the homeless. What police are calling ‘Operation Overpass” began Wednesday morning along I-75.

Michigan State Police Lt. Mike Shaw says where the city's homeless gather, you'll find large piles of debris.

"When we're done at all the different locations — which is about six of them — we'll probably, all said and done, [have] two dump trucks full of different things," said Shaw.

Shaw told WWJ's Mike Campbell those different things include clothes and garbage, as well as much larger items — all left behind by the homeless. Clearly, the activities of the <homeless $>$ are illustrated to be nuisances to the general public. Further, the Detroit police sanction the state of <homelessness > itself, forcibly relocating members of this population to various other areas, not all of which include shelters.

The rhetoric of these depictions of victimization indicate that even if the <criminal> acts exhibited by members of the lower class do not subject the upper classes to fear or violence, those antagonists are still a source of annoyance to the non-poor; hence, those who engage in it should be stigmatized by society or sanctioned by the law rather than tolerated. Internalizing this belief supports an ideology of classism by 
prioritizing the promotion of wealthy citizens' peace of mind over the promotion of poor citizens' social status. Further, in the very first sentence of his article, Campbell (2013) includes <homeless> people themselves in his reference to the underpass debris as “junk.” This dehumanizing language reduces the ability of news consumers to sympathize with the <homeless>. For one who internalizes these messages as truth, it becomes easy to hold members of upper classes in high social esteem while rendering members of lower classes, particularly the <homeless >, outside the scope of moral consideration.

The final way these articles construct the non-poor as victims of $\langle$ crime $>$ is subtle, yet still functions rhetorically by depicting the ordinary citizens as victimized by the actions of lower class antagonists. As explained in my ideographic analysis, several of the texts explain that Detroit's declaration of $<$ bankruptcy $>$ resulted in budget cuts to city services, including the police force; as a result, the police are not protecting the city as effectively (Fisher, 2013; Lewis, 2013; Neavling, 2013). Therefore, everyday citizens cannot rely upon the police as they once did. Further, Dudar (2013) and Lewis (2013) explain that Detroit Police Chief Craig is encouraging the citizens of Detroit to take responsibility for the safety of their communities themselves. Lewis explains that, left to their own devices to ensure their safety, citizens feel compelled to form community watch groups that combat <crime>, writing:

A group called the Detroit 300 echoed the police statement calling on every citizen to take responsibility for the increasing violence. Detroit 300 , founded by 
local activists, believes grassroots leadership is the best way to fight crime in their neighborhoods.

The Detroit 300 doesn't rely on the city's cash-strapped police force they make citizens' arrests themselves and put the responsibility for stopping the violence on every resident, urging people to get involved when they see or suspect a crime happening (2013).

As suggested here, groups like these feel that, due to high <crime> in the city, they must take control of enforcing the law without the assistance of the police. The rhetorical suggestion of this is that <crimes> committed by the lower class in the current conditions of Detroit push everyday working citizens into a position in which they feel forced to risk their own safety by protecting their communities. As such, the article further justifies the social contempt relayed by the dominant ideology to those perceived to be social antagonists - in this case, the poor.

The Non-Poor as Saviors. In my discussion of the fourth framing theme I uncovered in this analysis, I will demonstrate that the non-poor are not only represented in <crime > news narratives as the victims of the antagonistic lower class, but also as the potential heroes of the economic and social crises in Detroit. This representation, although distinct from the theme of victimization I just described, works to fortify Gramsci's (1971) hegemonic processes in the same way: it implicitly ranks the moral standing of different groups in society, who are essentially defined by their respective economic statuses. 
This has been displayed in some examples I have already provided. For instance, in the previous framing theme, I explored how Lewis's (2013) characterization of neighborhood watch groups like Detroit 300 could assert that the antagonism of the lower class demands that members of the wealthier class make sacrifices in order to protect their communities. Even though the upper classes are indeed victims in this way, Lewis's article suggests that these groups are doing very well in improving the conditions of their neighborhoods. In this way, non-poor citizens in Detroit are succeeding in ways that even the city's police force cannot. Further, this representation also serves to suggest that ordinary citizens are superior to the lower class antagonists, thus calcifying the classist ideology to which I have been referring.

Another example as to how members of the non-poor community are constructed as heroes may be seen in Campbell's (2013) discussion of Jerome Chandler, a member of an organization that cares for the <homeless $>$. Chandler is displayed as an extremely benevolent man who has volunteered for Project Helping Hands for six years, and in that time has aided many members of the <homeless> population to improve their living conditions. Such representations, such as the quotation from Chandler in the previous section of this chapter, support a classist ideology by suggesting that the non-poor are dedicated and hardworking people that have not only earned their privileged status, but also provide the means for members of the lower classes to survive.

Lastly, the non-poor are portrayed as saviors due to their potential ability to bolster the economies of Detroit and its surrounding communities. For example, Dudar (2013), Fisher (2013), and Maynard (2013) all suggest that the most likely way that the 
social ills of Detroit may be alleviated is the attraction of business leaders to the city, as they may create jobs for Detroit residents and would also spend money back into the local economy. Muller (2013), in her article suggesting that a major ill in Detroit is the large number of dilapidated structures, provides a more specific example as to how the non-poor can improve the conditions of the city:

Entrepreneur Bill Pulte, who earlier this year founded a non-profit called the Detroit Blight Authority, says the city has been going about blight elimination the wrong way. Knocking down nuisance drug houses one by one isn't enough to stop the deterioration, says the 25-year-old grandson of Pulte Homes founder William Pulte. He and his grandfather are advocating a more widespread, strategic approach to blight removal, including mass demolition of decrepit housing in troubled neighborhoods. Using the same economies of scale that apply when erecting houses, he said they can demolish homes for almost half the $\$ 10,000$ per home it costs the city.

This characterization of a member of a wealthier social class than most Detroit inhabitants indicates that those who belong to this social rank possess the material means, as well as the knowledge, required to benefit the city.

Overall, representations common to this theme construct the notion that the presence of a strong middle and upper class is a prior condition to salvaging Detroit and alleviating the harms to the area inflicted by its common residents who, by distinction, are obviously members of lower classes. According to the illustrations in these articles, the non-poor are able to offer expertise beyond the capabilities of the poor, further 
suggesting that those who are wealthy ought to be ideologically heralded as superior to those who are not wealthy. Additionally, the news stories suggesting that the access to money is the mechanism that will allow for the improvement of Detroit overtly claim that people in the middle and upper class are inherently better able to achieve progressive social change than the poor, while covertly constructing the possession of material wealth as synonymous to social power; together, the rhetoric of this portrayal also configures the logics of power around those with relative wealth.

Explication of Violence. The fifth notable frame I uncovered from my analysis pertains to several of the articles' thorough explanations of violence in Detroit. I have already provided several examples of these specific narratives in earlier sections, including Carlisle's (2013) description of the violence suffered by Travier's family, Lewis' (2013) detailed presentations of a litany of homicides, and Maynard's (2013) emotionally-charged accounts of the murders of Brown and Green. However, I will offer one further example that effectively illustrates this theme. Neavling's (2013) news article relates the story of a shooting that occurred in a Detroit barber shop. He writes:

Three people died and six were wounded in Detroit when a gunman opened fire on as many as 30 people who were gambling inside the back room of a barber shop, Detroit Police Chief James Craig said on Thursday.

Some of the men inside the room were armed and at least one fired back in a crime that stood out for its violence even at a time when the city, which filed for bankruptcy in July, is facing its highest murder rate in decades. 
"It certainly does rise up as one of Detroit's more violent incidents," Craig said in a Thursday morning news conference at the Detroit Police Department.... Two men died at the scene and a third died later at a local hospital, Craig said....

A witness in a pickup truck pulled up to the back of the barber shop and was fired upon by a gunman in another vehicle.

When the truck fled, the gunman got out of the vehicle and used a highpowered rifle to shoot through an open door to a small room in the back of the barber shop, Craig said.

There were between 20 and 30 people in the room, he said....

The door from the back room to the front of the barber shop opened inward, making it difficult to open as people pressed against it in an effort to get out. The victims were shot in the back room as they struggled to escape, Craig said.

As demonstrated here, many of the articles covering stories that involve violence leave little to the imaginations of their audiences.

The ideological consequences of the use of rhetoric containing such powerful sensory descriptors of violence are quite clear. Explicit, detailed accounts of these selected incidents make the <crime> narrative of Detroit seem more realistic than what actually occurs, and again, can result in Gerbner's (1973) process of acculturation. Thus, consumers of these news media would be more likely to accept the claim for which the rhetoric of these articles seems to be arguing: If poor neighborhoods are violent, then 
people should strive to avoid occupying social stations in which they may have to reside in poor neighborhoods, or even relate with others that do. Further, because these media frames have characterized the lower classes as the violent antagonists within the city, consumers are likely to stigmatize those who live in deprived conditions. This is especially true if my analysis of the second theme's representations is accurate. If the victims of <criminal> behavior are members of the middle and upper classes, then it is their blood that is being shed by the morally bankrupt <criminals> of the lower class.

Law as Benevolent. The last prevalent theme constructed by framing elements is the portrayal of the law and its mechanisms, such as the police, as a benevolent social force. First, though this has been relevant in several previous sections, I will re-establish that the texts explain that the fiscal pressure of $<$ bankruptcy $>$ on Detroit's public budgets has crushed the police force. As such, <criminals> are not adequately challenged by authorities of the law, creating the possibility for more <crime> in the city (Fisher, 2013; Lewis, 2013; Neavling, 2013).

Second, other articles discuss law enforcement in Detroit in a way that praises the force's ability to improve the city's conditions. Neavling (2013) explains that reformations in Detroit's police force have improved its ability to protect the city, and points to examples such as a drastically shorter average response time, decreasing crime rates, and the constructions of new formations within the department like a vice squad. Similarly, Hunter (2013) explains that the police forces have been able to deter seasonal crime by strategically increasing patrols in specific areas of the city. The clearest example of the positive portrayal of Detroit's police force, however, is present within the CBS 
News (2013) article with no byline that covered a crime sweep conducted by the department that resulted in the arrest of 32 offenders. The article states:

Residents' support for the police effort was clear.

“About damn time!” one man yelled.

"People started to clap, started to cheer; they'd been waiting too long," said Craig. "I talked to neighbors in the area, clapping and cheering, and the message is: Enough is enough.”

Craig [said] he even got a compliment from a man who had been arrested.

"One of the people taken into custody, as he was going on the bus, he looked at me and said, 'Chief, thank you.'” Craig said. "This was the second time an arrested thanked me - once when I was a young [police] officer in the LAPD; and now in Detroit as the police chief, he said, 'Thank you. My family will be safe."”

Craig said Friday's raid targeted one of the most crime-ridden, dangerous areas of the city. He said one aspect of crime fighting is psychological.

"We want to reduce the fear of crime," said Craig, "and we're doing that by doing this, because people will know Detroit police care about us because we're doing this."

The article's portrayal of the incident certainly constructs an image of the Detroit police and, by extension, the law it enforces, as a positive force for social change. Indeed, to the point where one of the offenders arrested in this crime sweep thanks the Chief of Police for his efforts, audiences are left with little room to question this endorsement. 
Essentially, these descriptions of law enforcement persuade news readers of the importance of maintaining the strength of the legal system. Granted, these articles only refer to the police and not the law or legal system as a whole, but as Lots (1991) argues, news coverage of $<$ crime $>$ constructs the police force as the personification of the law and representation of the overall legal system. Further, these articles clearly suggest that those who deviate from social expectations, characterized as behaviors of "order" in the context of law, ought to be swiftly acknowledged and punished by the police. This evaluation of the deserved consequences of <criminal behavior> supports an ideology that promotes rigid conformity to the norms of law and order.

Finally, the dichotomy between the negative impact of the reduction of law and positive effects of the magnification of law serves to indicate that legal codes are powerful mechanisms that promote positive behavior and check against behavior that is morally unsatisfactory. Of course, however, these legal codes are forged through the framework of a hegemonic ideology (Litowitz, 2000) that, as Potter and Kappeler (2012) explain, justifies inequalities in the use of the law to sanction deviant behaviors. In this way, we can observe how, even though Althusser (1971) would characterize the police as a repressive state apparatus instead of an ideological state apparatus, as evident through its common description as a "force," these departments still function to enforce an ideology. As such, the rhetorical construction of the law found in these articles corroborates Gramsci's (1971) notion of the hegemony as a social force capable of dominating the people it claims to serve and represent. 


\section{Cross-Referential Analysis}

Thus far, I have identified ideographs in various examples of news coverage of <crime> in Detroit, and also explored the various themes used by these articles to frame <criminal> behavior, as well as the persons involved in it and the places in which it takes place. Thus, in this last phase of my analysis, I seek to address an absence in scholarship of both media analysis and rhetorical criticism by discussing the relationship between ideographs and frames, if one exists at all. After surveying my findings from examining each concept independently, I can indeed conclude that ideographs and framing elements do function together to enhance the rhetorical impact of a text. More specifically, it is clear from my analysis that ideographs function to identify or describe certain persons, places, or events to an audience in such a way as to charge those descriptions with resounding meanings, thereby prescribing to the audience an ideological lens through which to view and evaluate these aspects of the stories. Further, frames operate on a macro-level by configuring the overall information present to fit within certain themes, providing readers with news stories that fit within socially constructed contexts for their understanding. Therefore, if we acknowledge that ideographs are used to add cultural meaning to the details of a piece of news coverage, while frames work to build the context of that news, we may realize that the two theoretical concepts may work together to construct an overall story in which the ideographic details amplify the political orientation of these thematic frames with additional ideological bias.

To better understand how ideographs and frames relate, it may be helpful to refer back to Railsback's (1983) theory of bounded language, which argues that ideographs are 
words used to promote the cultural ideals of a society, but whose meanings depend on the public's interpretation of their relationship between material reality and the symbolic conditions in which they are deployed. Moreover, Condit's (1987) elaboration of the theory of bounded language suggests that in societies discourse is primarily used to tell stories in which characterizations are used as descriptive labels for scenes, characters, and events, which fit into overarching plots that she refers to as narratives. For my purposes, then, we may conceptualize ideographs as these characterizations, whereas the framing themes serve to formulate cultural narratives. To demonstrate this phenomenon in my own texts, I will survey three examples of this relationship: the stigmatization of <criminals > in the plots of the narratives; the use of <crime>; <bankruptcy>; and $<$ homelessness > to construct < poverty>; and the use of <poverty> to describe the scenes and drive the plots of the stories.

$<$ Crime $>$ and Stigmatization. The first example of an interaction between ideographs and frames in these news articles is also likely the easiest to note: the articles' construction of narratives feature the lower class as antagonists, and heighten that resultant stigmatization by labeling them as <criminals>. The poor, who are already socially defined by their status as different from the middle and upper class (Michalowski, 2009), are demonized further through their receipt of this characterization suggesting that they are the ultimate social deviants - "ultimate" because, as I have explained throughout this thesis, they have failed to conform to cultural expectations that are considered to be so ideologically important that they are literally codified and established as a social structure. Casting this additional identity upon the poor further 
enables the non-poor to accept an ideology marked by its justification of class boundaries, as well as the disproportional distribution of social power across those constructs.

I have already provided several examples of this phenomenon, particularly in my discussion of <crime> as an ideograph and the framing of the poor as antagonists. In fact, each and every one of the articles I analyzed engages in this characterization to some degree. Buccellato's (2013) description of Detroit's < criminals> as living in <poverty> is perhaps the most clear instance of this labeling. Further, Hunt-Cooper's quotations in Carlisle's (2013) article further stigmatizes the poor with the $<$ criminal $>$ label, a description that is heightened when she directly contrasts the deviant antics of those individuals from the "housing projects" with the behaviors of the people with ordinary jobs that live in what Carlisle describes to be a "still solid neighborhood."

Indeed, exclusively casting poor people in the roles of antagonistic <criminals> in narratives about the detrimental impact of <crime> on Detroit clearly has profound and problematic implications on an ideology of classism. However, this <criminal> characterization of the poor is further exacerbated by the inclusion of middle and upper class representatives within those narratives to play the roles of the victims of <crime>, or else the conversely protagonistic forces that offer to improve conditions in the city pertaining to both <crime> and economics. Further, given that so often the <crimes> that are primarily featured and more heavily described in these articles are violent in nature as opposed to more common property <crimes>, the poor who are engaging in these so- 
called deviant behaviors do not appear to be motivated out of financial need, but instead, out of savagery that is beyond the understanding of ordinary, non-poor citizens.

Ultimately, all of this relates to Becker's (1963) labeling theory discussed in Chapter II. When news services that are both massively consumed by the public and are also generally assumed to present objective truisms include rhetoric that casts specific demographics in a negative light, the essentialized behaviors of those demographic groups are considered deviant. Individuals who are labeled deviant are immediately perceived by the bulk of society to be lesser beings than those who conform to societal expectations, resulting in hierarchies of cultural worth. Given that in these particular incidences the label of <criminal> is attached only to those of lower class, classist assumptions that justify disparities in wealth and social power seem justifiable to maintain, even to the point that the social ill that is <poverty > be ignored, and thus, perpetuated. Therefore, not only are the poor relegated to the peripheries of the social sphere, but they are also surrounded by systemically maintained social conditions. This is how Gramsci’s (1971) notion of cultural hegemony is able to persist.

Ideographs as Allusions to <Poverty>. Entman and Rojecki’s (2000) discussion of the news media's tendency to implicitly refer to < poverty $>$ through their coverage of its symptoms is again worth nothing in this section, because often those symptoms take the form of ideographs in these texts. Several examples of this phenomenon are given in the previous sections. For instance, Campbell (2013) continually discusses the presence of the <homeless> throughout various regions of Detroit to indicate that < poverty> is prevalent throughout the city, while Lewis (2013) uses other signs of <poverty> to 
describe Detroit, including not only "high unemployment," but also the ideographs $<$ crime> and <bankruptcy>.

Notably, Entman and Rojecki (2000) point out that when news media attempt to suggest that <poverty> is a relevant characteristic to a story, they tend to refer to the area they are discussing as frequently impacted by <crime>. This is clearly demonstrated in the CBS News (2013) article, in which the east side of Detroit, a region of the city wellknown to be in a state of 〈poverty>, is described to be one of the most "crime-ridden, dangerous areas of the city.” Another example of this may be found in Hunter's (2013) article, which states:

As part of the Police Department's effort to use statistics to fight crime, investigators have identified areas of the city that have seen the most holidayseason robberies over the past three years. The worst intersection: Michigan at Livernois in southwest Detroit, where there were nine robberies total from Nov. 1 through Dec. 31 over the past three years.

$<$ Bankruptcy $>$ is a powerful symptom of <poverty> as well, particularly when it is connected with $<$ crime $>$. In storeowner Bacall's quotations in Dudar's (2013) article, he states that he considers the east side of Detroit to be "the worst part of the bankrupt city," and then explains that "surrounding it are neighborhoods dotted with abandoned homes and stretches of tall grass where houses and businesses once stood." Further, Neavling's (2013) news story describes a shooting, and he writes: 
Some of the men inside the room were armed and at least one fired back in a crime that stood out for its violence even at a time when the city, which filed for bankruptcy in July, is facing its highest murder rate in decades.

Entman and Rojecki (2000) suggest that by tangentially covering <poverty> through elaborate discussions of its various effects, the news media satisfy their audience's desire to know about the quality of the conditions in society, yet do not do so in a way that allows these readers to acknowledge <poverty> as a social force with systemic causes. It is important to recognize that, as Derrida (1967/1976) argues, this symptomatic discussion of <poverty> functions only to supplement the representation of poor social conditions in the articles, not replace it. He writes: "The supplement supplements. It adds only to replace. It intervenes or insinuates itself in-the-place-of; if it fills, it is as if one fills a void" (p. 145). As such, the ideological connotations of <poverty> persist while the term itself hides beneath the articles' surface language. Again, as Derrida states, "One always inhabits, and all the more when one does not suspect it” (p. 24).

Although these symptoms may be related to <poverty>, and certainly worthy of news coverage because they, too, have detrimental social impacts, media's exclusive focus upon them only serves to distract the public from the genuine issues at hand. Deploying ideographs to describe the social scenes of these narratives as implicit indicators of <poverty> is particularly effective to this end, because ideographic terms like <crime>, <bankruptcy>, and <homelessness> are so culturally salient that readers are easily able to perceive stories pertaining to them as sufficient coverage of social 
conditions. This is an example of how certain assumptions about the nature of particular identities may constitute the common sense of society (Gramsci, 1971). As I have explained earlier in this chapter, the consequences of the implicit treatment of <poverty> in the news are quite significant, especially regarding the ideology of classism. If the social forces that create and perpetuate <poverty> go unquestioned by the public, it is easy for the classist ideology to continue to reign, fueling hegemony. Unfortunately, that is an ideology that justifies the subjugation of the poor by characterizing them as lazy and responsible for their own suffering.

$<$ Poverty $>$ and Causality. The final example of how ideographs and frames relate in these news articles pertains to the use of ideographs to characterize the social scene that drives the plots of narratives. In the context of these news stories, the ideograph implicitly used to describe the city of Detroit, yet not explained directly, is <poverty>, and plots of these narratives all include <criminal> behavior. Therefore, this relationship constructs the notion that <poverty> is at the root of <crime $>$ by creating the social conditions that force the poor in our culture to resort to such extreme deviance.

Buccellato (2013) provides us with the most explicit example of this assertion, indicating that the "third world" economic conditions of Detroit draw $<$ criminals $>$ together, thereby fostering gang activity. Further, Fisher (2013) writes that "it should be no surprise Detroit tops the Forbes list of the Most Dangerous Cities this year for the fifth year in a row." His rationale that Detroit's position on this list should be obvious is that the city and its residents are experiencing "crushing financial woes"; such an assertion 
indicates, of course, that < poverty $>$ must equate to high < crime $>$ rates. Muller's (2013) story also posits this causal relationship between <poverty> and <crime>:

Erasing debt from the balance sheet is critical to fixing the city. But so is erasing the blight that causes tax revenues to shrink and drives up the city's operating costs. Left untreated, blight is like a cancer that spreads, decreasing property values and leading to other social woes including arson and crime. If you're a drug dealer, pimp, or criminal on the run, an abandoned house is an ideal place to hide. Detroit police spend a disproportionate amount of their time trying to root them out of blighted neighborhoods.

By using stereotypical references to urban blight that allude to <poverty>, Muller is able to construct < poverty> as not only a direct cause of crime, but also as the cause of conditions that aid <criminals> in succeeding in their deviant endeavors.

Another way that these articles use < poverty> to propel their <crime> narratives is by deploying an opposing narrative that, as described in the preceding section, posits that people with wealth wield solutions both to <crime> and to conditions of <poverty>. These "savior" narratives configure a dichotomy between the upper classes as heroes and the lower classes as villains. Maynard (2013) provides a salient and explicit example of this dichotomy, writing that, "A Detroit News crime map, tracking crime for the past 15 months, shows multiple shootings and homicides across its neighborhoods, although downtown, where much of Detroit's recent investment has taken place, remains relatively safe." Clearly, areas of Detroit with money are comparatively much safer than the areas containing greater numbers of poor residents. Baldas' (2013) article includes another 
instance of this, in which she includes a quotation from a Detroit resident who derides the ability of emergency Detroit city manager Kevyn Orr to solve problems. She writes:

As for what concerns most Detroiters, crime topped that list, with 46 percent of respondents listing crime, drugs, gangs and violence as their top concern.

Among the respondents was Curtis Foster, a retiree who has lived in Detroit for more than six decades, raised his family here and put five children through college....

Foster also opposed the bankruptcy filing, and said he doubts that Orr can really fix anything.

"There's nothing he can do. In order to solve our problems here in the city of Detroit, it takes money," Foster said. "If he's not going to bring some money here, it's not going to help us. We have to bring in manufacturers. We have to bring in jobs. If Kevyn Orr can't do some of those things, he can't do nothing." As I have explained before, my understanding of <crime > does not divorce this form of social deviance from the context of the social conditions in which it occurs. <Poverty> may, and does, make one feel it is necessary to commit a <crime> to aid in his or her survival. However, given that $91 \%$ of citizens in the country demonstrate that they are capable of criminal behavior (Perez, 2010), and that the wealthy commit other, often more significant <crimes> at the same rate as members of the lower class (Michalowski, 2009), it is clear that <poverty> is not the primary instigation of such behavior. Therefore, rhetorically positioning < poverty> in such a way in these news stories inculcates readers with false beliefs regarding the social nature of poor people. It enables 
their cultural disregard, furthering the maintenance of an ideology propagating the moral superiority of the wealthy, and thus, their possession of comparatively high power. This propagation and internalization of such social logic fuels hegemonic processes that centralize upper classes in a core of power, at the expense of casting the poor as the subalterns in society (Gramsci, 1971).

\section{Conclusion}

In Chapter IV, I presented the results of the textual analysis I performed on news coverage of <crime> in Detroit. I first isolated ideographs in the texts and extrapolated their social meanings. Second, I described the pervasive frames within the articles and analyzed the cultural significance of their resultant representations. Third, I discussed the relationship between ideographs and the themes comprised of framing elements, thereby exploring how these mechanisms in discourse may interact on a rhetorical level. At each phase of my discussion, I explained how Gramsci’s (1971) description of cultural hegemony may aid in our comprehension as to how the dissemination of these rhetorical devices may enable an oppressive ideology to persist in its dominance.

In the fifth and final chapter of this thesis, I offer my concluding thoughts regarding the implications of my project. More specifically, I first discuss the contributions of my thesis to communication scholarship in terms of both critical theory and the methodology of rhetorical criticism. Second, I will elaborate upon the social impact of my findings, discussing more holistically the ways that these media representations allow repressive ideologies to maintain a status of dominance. Finally, I will describe how this thesis functions as a challenge to the problematic articulations of 
social relations within our media, and explore how we may use such projects as a means for progressive cultural change. 


\section{CHAPTER V \\ CONCLUSIONS}

In the previous chapter, I offered the findings of my analysis in three distinct parts: a phase of ideographic analysis, a phase of critical framing analysis, and a phase in which I cross-applied my findings from my independent analyses of ideographs and framing to uncover any potential relationships between the two concepts. Ultimately, I found several configurations of ideological rhetoric in my analysis of the news articles covering <crime> in Detroit, and I discussed how each of those discursive constructs in the media function as a mechanism by which hegemony perpetuates classism in our society.

Here in Chapter V, I present the conclusions we are able to draw from the findings I described in Chapter IV. First, I discuss the relevance of this project to academia, specifically as it pertains to rhetorical criticism and mass communication scholarship. Relatedly, I will also identify some potential limitations of my project that may serve as opportunities for future research endeavors. Second, I expound upon the significance of my findings to society by offering a more general discussion as to how these media representations enable hegemonic ideologies to persist in our culture. I will also explain how, through its problematization of the language of social relations in news media, this thesis contributes to an ongoing effort to effect progressive social change and disrupt the logics that enable disparate power relations. 


\section{Scholarly Implications}

My thesis functions to answer several questions posed by previous literature, as well as to fill gaps within the communication field and between notable academic concepts. First, I have aimed to provide further framing analysis that indicts hegemony and its problematic manifestations of social power, thereby addressing the concerns posed by Carragee and Roefs (2004) and Holstein (2003). Given that they argue in favor of any sustained criticism of discourse that aims to perpetuate subjugating ideologies, along with other scholars such as McKerrow (1989) and Zompetti (1997), my thesis may be viewed as a suitable contribution to this aim from both a perspective of scholarship in general, as well as one concerned with promoting social change.

Second, as I discussed in Chapter II, there is a surprising dearth of critical framing analysis as it applies to poverty, particularly from the approach of a rhetorical critic. Entman and Rojecki (2000) and Kendall (2011) both analyze the implications of classist framings, but offer no explicit connection to the notion of ideology as a whole. Indeed, Entman and Rojecki challenge the motivations of politicians in the construction of classist frames, whereas Kendall problematizes the concentrated control of these outlets on the part of a small number of corporations. However, it is important to note that the social motivations of these groups may only be surmised and not known. Further, even if we were truly able to understand the motivations of these powerful elites and challenge them, it is still important to note that it is not their agendas that create classist oppression in our culture in the first place; rather, it is the ideologies used to propagate it. As such, 
my analysis fills a void in critical framing research by addressing this phenomenon of ideological rhetoric.

Third and relatedly, my thesis also adds to the rather limited conversation in academia pertaining to the rhetoric of $\langle$ crime $\rangle$, specifically as it pertains to both the subject of social class and to the medium of news. Stephenson-Burton (1995) analyzes this matter, but considered the representations of upper class <criminals> in news rather than those pertaining to the lower class. Potter and Kappeler (2012), on the other hand, examine such representations of lower class <criminals>, but problematically assert that these instances of news do not draw even the most implicit of causal connections between $<$ crime> and <poverty>. Although their analyses are important, in wake of recent financial problems in our society, including the burst of the housing bubble, a deep recession, and high unemployment rates, it is important for this medium to be reinvestigated for evidence of such a relationship - which, as discussed thoroughly in the previous chapter, I discovered through my analysis.

Finally, perhaps the most important contribution my thesis offers to scholarship pertains to methodology. Prior to this project, there was no discernable work that sought to establish a connection between ideographs and framing, or their respective methods of analyses. As the publications of several scholars, as well as my own findings in Chapter IV, have demonstrated, both ideographic analysis and critical framing analysis can be very powerful and fruitful mechanisms for research and rhetorical investigation when used independently. However, they clearly relate to each other as well. Through the lens of Condit's (1987) expansion of Railsback's (1983) theory of bounded language, we may 
see how ideographs function to label and identify scenes, persons, and events with profoundly descriptive and culturally relevant characterizations. Further, we can begin to understand how these ideographic characterizations fit within the grander contexts of overall narratives within media messages, which are constituted by various themes of framing. Future researchers could seek to analyze other media messages through this approach to further expand upon the knowledge gleaned from their examinations, as well as to more thoroughly test the potential relationship between ideographs and frames.

In regards to further research then, I will now turn to addressing some of the limitations of my analysis and offering some suggestions as to how other scholars in the field may address these shortcomings in future projects. First, I selected only one city as a source of texts for my analysis. Future rhetorical critics may survey news from a greater number of locations so as to more extensively search for the ideological rhetoric that may exist. Other analyses could also aim to examine news from settings that are not urban in nature, so as to test the relevance of a setting's size and population, as well as its cultural significance to an overall society, to the presence of classism in rhetoric. Additionally, while expanding the number of texts to analyze was beyond the scope of this thesis given the variety of methods I used, considering more than just twelve articles would likely yield greater insights.

Moreover, perhaps the greatest limitation of my analysis is that I chose to investigate news coverage of the city in the United States that is widely regarded to be the location that, in recent days, suffers from the most severe social conditions in the country, at least in regards to <poverty> and <crime>. While I feel justified in my choice to begin 
the analysis of the rhetoric of class and crime with news coverage in Detroit for this very reason, much could be learned from additional research that investigates the representations of the relationship between class and <crime> in other cities - perhaps those not characterized as being so devastated by these conditions. Indeed, although Detroit is culturally significant, these qualities certainly cast it outside the "norm" for cities in the United States, as demonstrated by the demographic information and <crime> statistics I provide in Chapter III. It could be enlightening to analyze the news coverage of <crime > in cities more average in terms of both <crime> rates and economic status.

Furthermore, as explained in Chapter III, I did not analyze the images that accompanied the texts of these articles. Future research could examine the rhetorical impact of these images. Coleman (2010) writes that the presence of images in news articles can have significant impact on the overall frames of those articles, altering the meanings ascribed to the reported issues by the audience. Certainly, presenting images of the poor, such as <homeless>, in an article surveying the <crime> rates of Detroit, could powerfully influence readers' understandings as to the nature of <criminals>, as could supplementing these stories with images of other marginalized groups in society, such as African-Americans. Additional future research could examine the potential relationship between ideographs, news frames, and Iyengar and Kinder's (1987) priming theory. Based on my analysis, it seems likely that as a result of the ideologies promoted through the deployment of ideographs and frames within news articles, consumers will evaluate and judge the issues covered in those news stories in a manner consistent with the values endorsed by those ideologies. Finally, greater insights from all of my findings also would 
likely be gleaned from an application of the Weberian notion of the Protestant work ethic ideology (Beirne, 1979). Considering my discoveries in this context could offer more evidence for why both <criminals> and those living in <poverty> are stigmatized, and further, could explain in greater detail how conflating these two identities can result in extreme social demonization for persons essentialized as such.

\section{Cultural Implications}

After considering my findings in the previous chapter, it is quite clear that many of the discursive techniques used to represent and characterize <criminals> and <criminal> behavior are fundamentally classist and oppressive. Their deployment furthers a rhetorical strategy that allows an elite ideology to justify the subjugation of those in lower classes. Mass consumption of these thematic elements within news results in the creation and maintenance of artificial but strict notions of what constitutes normalized behaviors, as well as concepts of identity based upon one's social position. That consumption is especially problematic because, as Gramsci $(1971,2012)$ argues, news sources are largely conceived to be objective purveyors of social truisms.

The rigid social expectations fostered by this rhetoric may have severe consequences as they relate to <crime>. First, they allow the mass public to label members of the lowest classes in a society <criminal>, a label that, as Becker (1963) explains, restricts one's ability to interact with other members of society in acceptable ways, while also justifying the perceived moral and cultural superiority of the members of upper classes. Second, they reify the ability of the ideology to manifest itself into codified social structures through their depictions of the law as an instrument of salience. 
These representations enable social norms to become more than just expectations for behavior; indeed, cultural notions of acceptability and unacceptability in regards to behavior are dictated and actively enforced.

Additionally, as several scholars suggest, ideologies are capable of becoming so dominant in a society that even the elites to whom they lend power believe in their artificial constructions as natural (Hall, 1982; Makus, 1990; McGee, 1980a; McGee, 1980b). Further, Lotz (1991) suggests that representations of <crime> in the news can influence policymakers and police forces to alter their approaches to <crime> so as to answer their perceptions of growing trends in law-breaking. Therefore, should these social norms be internalized by those in control over law enforcement policy, they would allow for, or even encourage, increased scrutiny and coercive control over those who belong to the lower classes through Althusser's (1971) repressive state apparatuses, all in the name of protecting "contributing" members of society.

Finally, connecting my findings with Gerbner's (1973) theory of cultivation suggests that the representation of the relationship between <crime> and people living in <poverty> within the news media could profoundly impact the social expectations of consumers - particularly, those who do not live in conditions of <poverty> themselves. Absent an understanding of < poverty $>$ and the nature of poor people based on personal life experiences, audiences defer to acknowledging the representations in media artifacts such as these articles as social truths. As such, it is likely for an audience to conflate the social identities of the poor and <criminals>, and insert this essentializing construction within their cognitive schematics for social expectations. The implications of this 
acculturation process are vast. First, given the perceived objectivity of news sources (Gramsci, 1971, 2012) as well as their accessibility to a mass population, their rhetorical constructions are persistently posited within the cultural mainstream of information. Second, Gerbner himself explains that a primary impact of consumers' incorporation of these representations within acculturation processes is that they are likely to be afflicted with the mean world syndrome - a belief that the world is more dangerous and its population more malevolent than they actually are. Consumers' acceptance of this belief allows them to justify treating the Others they fear with intolerance and even hostility.

In analyzing this series of articles regarding news coverage in <crime> in Detroit, I have not only exposed an instance of hegemony, but also outlined an example of a process by which the dominant ideology that undergirds it comes to persist. The dissemination of rhetoric through media outlets perceived to be purveyors of objective information allows for the prominent ideology in a society to maintain its position of dominance. This occurs through that ideology's influence upon the selection of which details and characterizations are used to provide information in news reports, as well as the themes used to contextualize them, at the consistent preclusion of other perspectives that may cause the public to question or even challenge the norms endorsed by that ideology.

In this thesis, I have attempted to engage in what McKerrow's (1989) critical rhetoric. Overall, I have isolated the ideology of classism as a source of oppression, identified the news media as a cultural mechanism that promote it, and investigated the discourse of these texts to discern the ways they might construct social structures that 
enable classist assumptions. Hart and Daughton (2004) indicate that rhetorical criticism in and of itself is a powerful means by which one might begin to challenge manifestations of cultural subjugation. As Zompetti (1997) argues, it is not only necessary to discover instances of hegemonic oppression, but also important to expose the mechanisms by which they sustain themselves, as well as the sources from which they originate. It is clear that rhetoric that is both powerful and problematic pervades many different media and channels, including those society at large deems to be objective and trustworthy. Maintaining this process of critical exposure is vital to challenging common sense assumptions about the relationship between crime and class, disrupting that relationship as a means of oppression, and rearticulating social understandings about class and criminal behavior. 


\section{REFERENCES}

Al Jazeera America (2014). Official website. Retrieved January 25, 2014 from http://america.aljazeera.com/

Althusser, L. (1971). On ideology. Brooklyn: Verso.

Angelova, K. (2012, Oct. 2). Bleak photos capture the fall of Detroit. Business Insider. Retrieved Dec. 20, 2013 from http://www.businessinsider.com/the-incredible decline-of-detroit0-photos-2012-10?op=1

Associated Press (2011, Nov. 1). Circulation numbers for the 25 largest newspapers. The Boston Globe. Retrieved February 8, 2014 from http://www.boston.com/business/ technology/articles/2011/11/01/circulation_numbers_for_the_25_largest_ newspapers/

Associated Press (2012, Oct. 30). Circulation numbers for the 25 largest newspapers. Yahoo. Retrieved February 8, 2014 from http://finance.yahoo.com/news/ circulation-numbers-25-largest-newspapers-195059172--finance.html

Baldas, T. (2013, Sep. 24). Poll: Detroiters worry about crime, city's direction. USA

Today. Retrieved Dec. 4, 2013, from http://www.usatoday.com/story/ news/nation/2013/09/23/detroit-poll/2858837/

Beck, G. (2010). Arguing with idiots: How to stop small minds and big government. New York City: Threshold Editions.

Becker, H. (1963). Outsiders: Studies in the sociology of deviance. London: The Free Press.

Beirne, P. (1979). Ideology and rationality in Max Weber's sociology of law. Research in Law and Sociology, 2, 103-131.

Bennett-Carpenter, B., \& McCallion, M. (2012). Specialized, ecclesial ideography: The $<$ new evangelization> in the Catholic church. Michigan Academician, 41, 1-21.

Bourdieu, P. (1999). Language and symbolic power. Cambridge: Harvard University Press. 
Brantley, C., Frost, D., Pfeffer, C., Buccigrossi, J., \& Robinson, M. (2003). Class: Power, privilege, and influence in the United States. University of Maryland Office of Diversity Education and Compliance. Retrieved May 4, 2013, from http://www.odec.umd.edu/CD/CLASS/BRANTLEY.PDF

Brown, S. (2003). Crime and law in media culture. Philadelphia: Open University Press.

Bruner, J. (2012, Jun. 8). The media map: Who's reading what and where. Forbes. Retrieved February 8, 2014 from http://www.forbes.com/special-report/2012/ media-map.html

Buccellato, J. (2013, Oct. 31). Gangs of Detroit: Examining youth violence. CBS Detroit. Retrieved Dec. 5, 2013, from http://detroit.cbslocal.com/2013/10/31/gangs-of detroit-examining-youth-violence/

Byers, D. (2012, Aug. 7). 'Time Magazine' still on top in circulation. Politico. Retrieved February 8, 2014 from http://www.politico.com/blogs/media/2012/08/timemagazine-still-on-top-in-circulation-131349.html

Campaign to End Homelessness (2014). Region 8. Regional Data from Michigan's Campaign. Retrieved February 14, 2014, from http://www.thecampaigntoend homelessness.org/MichigansCampaign/TheData.aspx

Campbell, M. (2013, Sep. 15). Trash removed, homeless relocated in underpass cleanup effort. CBS Detroit. Retrieved December 5, 2013, from http://detroit.cbslocal.com /2013/09/25/trash-removed-homeless-relocated-in-underpass-cleanup-effort/

Carlisle, J. (2013, Oct. 20). Even in Detroit's best neighborhoods, home invasions steal residents' sense of peace. Detroit Free Press. Retrieved Dec. 4, 2013, from http://www.freep.com/article/20131020/COL46/310200074/burglaries-detroit thieves clearance-rates-safety-security-jefferson-chalmers

Carragee, K., \& Roefs, W. (2004). The neglect of power in recent framing research. Journal of Communication, 52, 213-233.

CBS Detroit (2013, Nov. 15). 32 arrested in biggest Detroit crime sweep in 20 years; neighbors clap and cheer. Retrieved December 5, 2013, from http://detroit. cbslocal.com/2013/11/15/32-arrested-in-biggest-detroit-crime-sweep-in-20-years -neighbors-clap-and-cheer/

CBS Detroit (2014). Official website. Retrieved January 25, 2014 from http://detroit.cbslocal.com/ 
City-Data (2014). Detroit, Michigan. Retrieved February 14, 2014 from http://www.city data.com/city/Detroit-Michigan.html

Coleman, R. (2010). Framing the pictures in our heads: Exploring the framing and agenda-setting effects of visual images. In P. D’Angelo and J. Kuypers (eds.), Doing news framing analysis: Empirical, theoretical, and normative perspectives. (pp. 233-261). New York City: Routledge.

Condit, C. (1987). Democracy and civil rights: The universalizing influence of public argument. Communication Monographs, 54, 1-18.

Connelly, E. (2012). State secrets and redaction: The interaction between silence and ideographs. Western Journal of Communication, 76, 236-249.

Cormack, M. (1992). Ideology. Ann Arbor: University of Michigan Press.

D’Angelo, P. (2002). News framing as a multiparadigmatic research program: A response to Entman. Journal of Communication, 52, 870-888.

Derrida, J. (1967/1976). Of grammatology (G. C. Spivak, Trans.). Baltimore, MD: Johns Hopkins University Press.

Derrida, J. (1972/1991). "Signature event context" in margins of philosophy (1972). In Peggy Kamuf (Ed.), A Derrida reader: Between the blinds (pp. 80-111). New York: Columbia University Press.

Detroit Free Press (2014). Official website. Retrieved January 25, 2014 from http://www.freep.com/

Detroit News (2014). Official website. Retrieved January 25, 2014 from http://www.detroitnews.com/

Detroit Police Department (2013). Recent crime statistics. Crime Statistics. Retrieved February 14, 2014, from http://www.detroitmi.gov/DepartmentsandAgencies/ PoliceDepartment/CrimeStatistics.aspx

Dudar, H. (2013, Aug. 30). Detroit: Closed for business. Al-Jazeera. Retrieved Dec. 4, 2013, from http://america.aljazeera.com/articles/2013/8/30/detroit-closed forbusiness.html

Edmonds, R., Gustkin, E., \& Rosenstiel, T. (2011). Newspapers: By the numbers. The State of the News Media 2011: An Annual Report on American Journalism. Retrieved February 8, 2014 from http://stateofthemedia.org/2011/newspapers essay/data-page-6/ 
Entman, R. M. (1993). Framing: Toward clarification of a fractured paradigm. Journal of Communication, 43, 51-59.

Entman, R. M., \& Rojecki, A. (2000). The Black image in the White mind: Media and race in America. Chicago: The University of Chicago Press.

Ewalt, J. (2012). A colonialist celebration of national <heritage>: Verbal, visual, and landscape ideographs at homestead national monuments of America. Western Journal of Communication, 75, 367-385.

Finocchiaro, M. (1998). Democracy, philosophy, and Gramsci. The Philosophical Forum, 29, 119-137.

Fisher, D. (2013, Oct. 22). Detroit again tops list of most dangerous cities, as crime rate dips. Forbes. Retrieved Dec. 4, 2013, from http://www.forbes.com/sites/ danielfisher/2013/10/22/detroit-again-tops-list-of-most-dangerous-cities-but crime-rate-dips/

Fontana, B. (2005). The democratic philosopher: Rhetoric as hegemony in Gramsci. Italian Culture, 23, 97-123.

Forbes (2014). Official website. Retrieved January 25, 2014 from http://www.forbes.com/home_usa/

Foss, S. (2009). Rhetorical criticism: Exploration and practice (4th ed.). Prospect Heights, IL: Waveland.

Gamson, W., \& Lasch, K. (1983). The political culture of social welfare policy. In S. Spiro \& E. Yaar (Eds.), Evaluating the welfare state (pp. 397-415). New York: Academic Press.

Gerbner, G. (1973). Cultural indicators: The third voice. In G. Gerbner, L. Gross, \& W. Melody (Eds.), Communication technology and social policy (pp. 553-573). New York: Wiley.

Ghallager, J. (2013, Apr. 18). Metro Detroit job sprawl worst in U.S.; many jobs beyond reach of poor. Detroit Free Press. Retrieved Dec. 20, 2013, from http://www.freep.com/article/20130418/BUSINESS06/304180118/jobs-sprawl -Detroit-Brookings-Institution

Giddens, A. (1996). Introduction to sociology (2nd ed). New York: W. W. Norton \& Company. 
Goffman, E. (1974). Frame analysis: An essay on the organization of experience. New York: Harper and Row.

Gould, L. (2009). Privilege and the construction of crime. In The Criminology and Criminal Justice Collective of Northern Arizona University (Ed.), Investigating difference: Human and cultural relations in criminal justice (2nd ed, pp.23-38). Upper Saddle River, NJ: Pearson.

Gouldner, A. (1982). The dialectic of ideology and technology. New York City: Oxford University Press.

Gramsci, A. (1971). Selections from the prison notebooks (Q. Hoare \& G. N. Smith, Trans.). New York: International Publishers.

Gramsci, A. (2012). Selections from cultural writings (W. Boelhower, Trans.). Chicago: Haymarket Books.

Grandoni, D. (2012, Mar. 23). A map of Al-Jazeera's U.S. fans. The Wire. Retrieved February 8, 2014 from http://www.thewire.com/business/2012/03/map-al -jazeeras-us-fans/50255/

Guess, T. J. (2006). The social construction of Whiteness: Racism by intent, racism by consequence. Critical Sociology, 32, 649-673

Hall, S. (1986). The problem of ideology: Marxism without guarantees. Journal of Communication Inquiry, 10, 28-43.

Hamilton, H. (2012). Can you be patriotic and oppose the war? Arguments to co-opt and refute the ideograph of patriotism. Controversia, 8, 13-35.

Hart, R., \& Daughton, S. (2004). Modern rhetorical criticism (3rd ed.). Boston: Pearson.

Hawkes, D. (2003). Ideology: The new critical idiom. New York: Routledge.

Hollihan, T., \& Riley, P. (1993). Rediscovering ideology. Western Journal of Communication, 57, 272-277.

Holstein, L. (2003). In defense of framing: Bringing hegemony back in. Paper presented at the annual meeting of the International Communication Association, San Diego.

Homefacts (2014). Detroit, MI crime report. Crime Stats. Retrieved February 14, 2014 from http://www.homefacts.com/crime/Michigan/Wayne-County/Detroit.html 
Howitt, D. (1998). Crime, media, and the law. Ann Arbor: Wiley.

Hunter, G. (2013, Dec. 28). Detroit police focus on high-crime areas during the holidays. The Detroit News. Retrieved December 31, 2013, from http://www.detroitnews. com/article/20131228/METRO01/312280022/1410/METRO01/Detroit-police -focus-on-high-crime-areas-during-holidays

Iyengar, S. (1987). Television news and citizens' explanations of national affairs. American Political Science Review, 81, 815-831.

Iyengar, S. (1989). How citizens think about national issues: A matter of responsibility. American Journal of Political Science, 33, 878-900.

Iyengar, S. (1991). Is anyone responsible? How television frames political issues. Chicago: University of Chicago Press.

Iyengar, S., \& Kinder, D. R. (1987). News that matters: Television and American opinion. Chicago: University of Chicago Press.

Jensen, T. (2014, Jan. 30). Fox once again leads 'most trusted' and 'least trusted' list. Public Policy Polling. Retrieved February 8, 2014 from http://www.publicpolicypolling.com/pdf/2014/PPP_Release_National_130.pdf

Kahneman, D., \& Tverskey, A. (1979). Prospect theory: An analysis of decision under risk. Econometrica, 47, 263-91.

Katz, J. (1987). What makes crime “news?” Media, Culture, and Society, 9, 47-75.

Kaufman, S., Elliot, M., \& Shmueli, D. (2003). Frames, framing and reframing. Beyond Intractability. Retrieved May 5, 2013, from http://www.beyondintractability.org/ biessay/framing

Keith, W., \& Lundberg, C. (2008). The essential guide to rhetoric. New York: Bedford/St. Martin's Publishing.

Kendall, D. (2011). Framing class: Media representations of wealth and poverty in America. Lanham, MD: Rowman and Littlefield.

Kuypers, J. (2010). Framing analysis from a rhetorical perspective. In P. D'Angelo \& J. Kuyper (Eds.), Doing news framing analysis: Empirical and theoretical perspectives (pp. 286-311). New York: Routledge. 
LeDuff, K. (2012). The real price of oppression: Fox News coverage of the Virginia Tech shooter. In C. Campbell, K. LeDuff, C. Jenkins, \& R. Brown (Eds.) Race and news: Critical perspectives (pp. 161-76). New York: Routledge.

Lee, E. (2013, Apr. 30). 'New York Times' tops 'USA Today' to become no. 2 U.S. paper. Bloomberg. Retrieved February 8, 2014, from http://www.bloomberg.com /news/2013-04-30/new-york-times-leads-major-newspapers-with-18-circulationgain.html

Lewis, R. (2013, Nov. 9). Detroit gun violence claims 17 lives in past 10 days. $A l$ Jazeera. Retrieved December 4, 2013, from http://america.aljazeera.com/articles/ 2013/11/9/detroit-violenceskyrocketsamidbankruptcyrestructuring.html

Lichterman, J., \& Woodall, B. (2013, Dec. 13). In largest-ever U.S. city bankruptcy, cuts coming for Detroit creditors, retirees. Reuters. Retrieved Dec. 4, 2013, from http://www.reuters.com/article/2013/12/03/us-usa-detroit-bankruptcy-judge idUSBRE9B20PZ20131203

Lincoln, Y., \& Guba, E. (1985). Naturalistic inquiry. Beverly Hills, CA: Sage Publications, Inc.

Litowitz, D. (2000). Gramsci, hegemony, and the law. Brigham Young University Law Review, 515-551.

Lotz, R. (1991). Crime and the American press. Ann Arbor: Praeger.

Lucaites, J., \& Condit, C. (1990). Reconstructing <equality>: Culturetypal and counter cultural rhetorics in the martyred Black vision. Communication Monographs, 57, $5-24$.

Makus, A. (1990). Stuart Hall's theory of ideology: A frame for rhetorical criticism. Western Journal of Speech Communication, 54, 495-514.

Mann, G. (2008). Time, space, and money in capitalism and communism. Human Geography, 1(2), 4-12.

Mann, G. (2013). State of confusion: Money and the space of civil society in Hegel and Gramsci. In M. Ekers, G. Hart, S. Kipfer, \& A. Loftus (Eds.) Gramsci: Space, nature, and politics (pp. 104-20). Malden, MA: Wiley-Blackwell.

Marx, K. (1990). Capital: A critique of political economy (P. Fowkes, Trans.). New York: Penguin. 
Marx, K. \& Engels, F. (1987). Collected works, Volume 29 (1857-1861) (R. Dixon, Trans.). New York: International Publishers.

McKerrow, R. E. (1989). Critical rhetoric: Theory and praxis. Communication Monographs, 56, 91-112.

Maynard, M. (2013, Nov. 18). Shootings cast pall over Detroit's comeback narrative. Time. Retrieved Dec. 4, 2013, from http://nation.time.com/2013/11/18/shootings -cast-pall-over -detroits-comeback-narrative/

McGee, M. (1980a). The "ideograph": A link between rhetoric and ideology. Quarterly Journal of Speech, 66, 1-16.

McGee, M. (1980b). The "ideograph" as a unit of analysis in political argument. Paper presented at the National Communication Association/American Forensic Association 1st Conference on Argumentation, Alta.

Michalowski, R. (2009). Social class, crime, and justice. In The Criminology and Criminal Justice Collective of Northern Arizona University (Ed.), Investigating difference: Human and cultural relations in criminal justice (2nd ed, pp. 55-73). Upper Saddle River, NJ: Pearson.

Moore, M. P. (1997). The cigarette as representational ideograph in the debate over environmental tobacco smoke. Communication Monographs, 64, 47-64.

Muller, J. (2013, Aug. 26). Erase blight. Erase debt. In bankrupt Detroit, it's all the same. Forbes. Retrieved December 4, 2013, from http://www.forbes.com/sites/ joannmuller/2013/08/26/erase-blight-erase-debt-in-bankrupt-detroit-its-all-the -same/

Neavling, S. (2013, Nov. 7). Three dead, six hurt in attack on Detroit gambling room. Reuters. Retrieved December 4, 2013, from http://www.reuters.com/article/2013/ 11/07/us-usa-crime-detroit-idUSBRE9A601620131107

Nelson, T., Oxley, Z., \& Clawson, R. (1997). Toward a psychology of framing effects. Political Behavior, 19, 221-246.

Nielson, M., Jones, L., \& Perry, B. (2009). Investigating difference. In The Criminology and Criminal Justice Collective of Northern Arizona University (Ed.), Investigating difference: Human and cultural relations in criminal justice $\left(2^{\text {nd }}\right.$ ed., pp. 2-9). Upper Saddle River, NJ: Pearson. 
Palczewski, C. (2005). The male Madonna and the feminine Uncle Sam: Visual argument, icons, and ideographs in 1909 anti-woman suffrage postcards. Quarterly Journal of Speech, 91, 365-394.

Perez, J. S. (2010). Social economic status/Class criminal justice in the U.S. Retrieved from Columbia University Academic Commons.

Potter, G., \& Kappeler, V. (2012). Media, crime, and hegemony. In G. Potter \& V. Kappeler (Eds.), Crime, media and the perpetuation of racism, sexism, and class stereotypes (pp. 3-17). Jefferson: McFarland Press.

Railsback, C. (1983). Beyond rhetorical relativism: A structural-material model of truth and objective reality. The Quarterly Journal of Speech, 69, 351-363.

RealtyTrac (2014). Detroit real estate statistics \& foreclosure trends summary. Retrieved March 4, 2014, from http://www.realtytrac.com/statsandtrends/mi/wayne -county/Detroit

Reiman, J. (1998) The rich get richer and the poor get prison: Ideology, Class, and criminal justice. Needham Heights, MA: Allyn and Bacon.

Reuters. (2014). In Encyclopaedia Britannica. Retrieved February 8, 2014 from http://www.britannica.com/EBchecked/topic/500259/Reuters

Reuters (2014). Official website. Retrieved January 25, 2014, from http://www.reuters.com/

Roach, T. (2012). The social construction of methamphetamine in the print media. In G. Potter \& V. Kappeler (Eds.), In Crime, media and the perpetuation of racism, sexism, and class stereotypes (pp. 64-77). Jefferson: McFarland Press.

Saba, J. (2011, Mar. 14). Online readership and ad revenue overtake newspapers.

Reuters. Retrieved February 8, 2014 from http://www.reuters.com/article/2011/03 /14/us-media-readership-idUSTRE72D0WC20110314

Scheufele, D. (1999). Framing as a theory of media effects. Journal of Communication, 49, 103-122.

Siegel, L. (2009). Criminology $\left(10^{\text {th }}\right.$ ed). Belmont: Thomson Wadsworth.

Sillars, M., \& Gronbeck, B. (2001). Communication criticism. Prospect Heights, IL: Waveland. 
Smith, K. (2010). Gramsci at the margins: Subjectivity and subalternity in a theory of hegemony. International Gramsci Journal, 1, 39-50.

Snow, D., Rochford, E., Worden, S., \& Benford, R. (1986). Frame alignment processes, micromobilization, and movement participation. American Sociological Review, $51,464-481$.

Stephenson-Burton, A. (1995). Through the looking glass: Public images of white collar crime. In D. Kidd-Hewitt \& R. Osborne (Eds.), Crime and the media: The postmodern spectacle (pp. 131-165). University of California: Pluto Press.

Therborn, G. (1978). What does the ruling class do when it rules? Thetford, Norfolk: Lowe \& Brydone.

Therborn, G. (1980). The ideology of power and the power of ideology. Brooklyn: Verso.

Thompson, J. B. (1990). Ideology and modern culture (pp. 28-73). Stanford: Stanford University Press.

Time (2014). Official website. Retrieved January 25, 2014 from http://time.com/

Tuchman, G. (1978). Making news: A study in the construction of reality. Ann Arbor: The Free Press.

USA Today (2013, Oct. 31). 'USA Today' regains national circulation lead. Retrieved February 8, 2014, from http://www.usatoday.com/story/money/business/2013/10/ 31/aamnewspaper-circulation/3323743/

USA Today (2014). Official website. Retrieved January 25, 2014 from http://www.usatoday.com/

United States Census Bureau (2013, Dec. 17). Detroit, Michigan. State and County Quick Facts. Retrieved Jan. 2, 2013, from http://quickfacts.census.gov/qfd/ states/26/2622000.html.

White, R. \& Perrone, S. (2005). Crime and social control (2nd ed). Melbourne, Australia: Oxford University Press.

Wonders, N. (2009). Conceptualizing difference. In The Criminology and Criminal Justice Collective of Northern Arizona University (Ed.), Investigating difference: Human and cultural relations in criminal justice (2nd ed, pp. 10-22). Upper Saddle River, NJ: Pearson.

Wykes, M. (2001). News, crime and culture. London: Pluto Press. 
Zompetti, J. (1997). Toward a Gramscian critical rhetoric. Western Journal of Communication, 61, 66-86. 